\title{
A influência do Método Canguru no tempo de internação do recém-nascido prematuro em unidades hospitalares: uma revisão integrativa
}

\author{
The influence of the Kangaroo Method on the \\ time of hospitalization of the premature infant \\ in hospital units: na integrative review
}

\author{
Ariana Prazeres dos Santos ${ }^{1}$ \\ Catharina Oliveira Sapucaia ${ }^{2}$
}

\begin{abstract}
${ }^{1}$ Autora para correspondência. Secretaria da Saúde do Estado da Bahia (Salvador). Bahia, Brasil. ary_prazeres12@hotmail.com ${ }^{2}$ Unidade de Terapia Intensiva Neonatal da Maternidade de Referência Professor José Maria de Magalhães Neto; Centro Universitário UniRuy
\end{abstract} (Salvador). Bahia, Brasil. cathy_sapucaia@hotmail.com

RESUMO | INTRODUÇãO: A prematuridade no Brasil corresponde a $12,4 \%$ dos nascidos vivos e é definida como o nascimento inferior a 37 semanas de gestação. Por conta da imaturidade de órgãos e sistemas, o recém-nascido pode apresentar diversas complicações e consequentemente maior tempo de internação nas unidades hospitalares, levando à uma maior morbidade e mortalidade nesta população. O período de internação dificulta o estabelecimento do vínculo entre os recém-nascidos e os seus pais. Por isso, técnicas como o método canguru que visam fortalecer esse vínculo são cada vez mais estudadas e aplicadas nestas unidades. O objetivo do presente trabalho é avaliar através de uma revisão de literatura se o método canguru influencia no tempo de internação do recém-nascido prematuro em unidades hospitalares. MÉTODO: Trata-se de um estudo de revisão integrativa de literatura com busca de artigos nas bases de dados eletrônicas Portal Regional da Biblioteca Virtual em Saúde (BVS), PubMed, Cochrane, Physiotherapy Evidence Database (PEDro) e EBSCO host com a utilização do cruzamento de quatro descritores em inglês e português indexados respectivamente no Medical Subject Headings (MeSH) e Descritores em Ciências da Saúde (DeCS). Foram inclusos estudos publicados no período 2008 a 2020. RESULTADOS: Foram incluídos 22 artigos com um total de 7.564 pacientes e sete parâmetros relacionados à alta hospitalar. Os resultados evidenciaram melhora nos sinais vitais, quadro álgico, sono, taxas de crescimento, regulação hormonal e facilitação neurocomportamental. CONCLUSÃO: Os achados indicaram que o método canguru influencia na melhora do quadro clínico do recém-nascido prematuro, contribuindo para uma meIhor estabilização do quadro e consequente redução no período de internamento.

PALAVRAS-CHAVE: Método Canguru. Prematuridade. Tempo de hospitalização.
ABSTRACT | INTRODUCTION: Prematurity in Brazil corresponds to $12.4 \%$ of live births and is defined as birth less than 37 weeks of gestation. Due to the immaturity of organs and systems, the newborn can present several complications and, consequently, a longer stay in hospital units, leading to greater morbidity and mortality in this population. The hospitalization period makes it difficult to establish a bond between newborns and their parents. For this reason, techniques such as the kangaroo method that aims to strengthen this bond are increasingly studied and applied in these units. The present study aims to assess, through a literature review, whether the kangaroo method influences the length of hospital stay of premature newborns in hospital units. METHOD: This is an integrative literature review study with the search for articles in the electronic databases Regional Portal of the Virtual Health Library (VHL), PubMed, Cochrane, Physiotherapy Evidence Database (PEDro), and EBSCO host with the crossing of four descriptors in English and Portuguese indexed respectively in the Medical Subject Headings (MeSH) and Health Sciences Descriptors (DeCS). Studies published from 2008 to 2020 were included. RESULTS: 22 articles were included with a total of 7.564patients and seven parameters related to hospital discharge. The results showed an improvement in vital signs, pain, sleep, growth rates, hormonal regulation, and neurobehavioral facilitation. CONCLUSION: The findings indicated that the kangaroo method influences the improvement of the clinical condition of the premature newborn, contributing to better stabilization of the condition and consequent reduction in the period of hospitalization.

KEYWORDS: Kangaroomethod. Prematurity. Time of hospitalization. 


\section{Introdução}

O termo prematuridade é definido, segundo a Organização Mundial de Saúde (OMS), como o nascimento abaixo de 37 semanas de gestação. Ele pode ser classificado a depender da idade gestacional ${ }^{1}$. A etiologia do parto prematuro é multifatorial e pode ser causado por diversas situações que levem a paciente ter contrações uterinas antes do tempo previsto, como, por exemplo, gestação múltipla, uso de drogas, abortos de repetição, hipertensão arterial, sofrimento fetal, gravidez na adolescência, entre outros. A incidência da prematuridade varia de acordo com a região e com a condição socioeconômica da população? .

Devido à imaturidade de órgãos e sistemas, o RN pode apresentar diversas complicações resultantes da dificuldade de adaptação à vida extrauterina, levando a maior mortalidade e morbidade nessa população e consequentes gastos na medida em que o parto prematuro demanda assistência e cuidados de maior nível de complexidade? .

A alta hospitalar é um momento de grande expectativa. No entanto, esses recém-nascidos, devido ao grande número de complicações, têm um tempo prolongando de permanência nas unidades hospitalares, se comparado aos recém-nascidos a termo. Associado a isso, diversos fatores, como peso, sinais vitais e dificuldade de sucção, interferem nessa alta ${ }^{3}$. No entanto, os avanços tecnológicos na área da saúde são evidentes e as novas abordagens trazem mudanças nas unidades de terapia intensiva neonatal (UTIN) e em outras unidades hospitalares que levam ao aumento da sobrevida de recém-nascidos cada vez mais prematuros e com pesos de nascimento mais baixos 4 .

O período de internação na UTIN e nas outras unidades hospitalares dificulta o estabelecimento do vínculo e apego com os pais, em particular, na essencial relação com a mãe. Por isso técnicas que também visam fortalecer esses vínculos são cada vez mais estudadas e aplicadas nessas unidades, como o método canguru ${ }^{5}$.
O método canguru foi criado em 1979 na Colômbia, com objetivo de reduzir os custos perinatais e promover, através do contato pele a pele, maior vínculo afetivo, maior estabilidade térmica e melhor desenvolvimento. O método é desenvolvido em três etapas: a primeira tem início no pré-natal da gestação. Nesta etapa, é priorizado o acolhimento aos pais e famílias, apoio ao acompanhante da mulher durante o parto e nos cuidados gestacionais. Além disso, esta etapa envolve também a internação do recém-nascido na UTI neonatal e/ou na UCINCo. Já a segunda etapa é realizada na UCINCa, com atenção especial ao aleitamento materno. A terceira etapa é o momento em que os recém-nascidos recebem alta e serão acompanhados de forma compartilhada pela equipe do hospital e da atenção básica do método canguru ${ }^{6}$.

Por isso, revisar como o método canguru pode influenciar nessa população é de extrema importância, já que é uma prática de baixo custo e de fácil adesão. Dessa forma, o objetivo do presente trabalho é avaliar através de uma revisão de literatura se o método canguru influencia no tempo de internação do recém-nascido prematuro em unidades hospitalares.

\section{Material e métodos}

\section{Estratégia de busca}

O presente artigo é uma revisão integrativa, onde foram aplicadas algumas das regras do Transparent Reporting of System Reviews and Meta analyses-PRISMA para sua elaboração. Foram delimitadas as seguintes etapas: identificação do tema; seleção da questão de pesquisa; estabelecimento de critérios para inclusão e exclusão de estudos; definição das informações a serem extraídas dos estudos selecionados, avaliação dos estudos incluídos na revisão; interpretação e apresentação dos resultados em formato de tabelas; apresentação da revisão e síntese do conhecimento ${ }^{38}$.

Foi realizada uma busca na literatura publicada nos últimos 12 anos, utilizando as bases de dados: Portal Regional da Biblioteca Virtual em Saúde (BVS), PubMed, Cochrane, Physiotherapy Evidence Database (PEDro) e EBSCOhost. 


\section{Descritores}

Para definição da estratégia de busca, foram utilizados o Decs (Descritores da Ciência e Saúde) e o MESH (Medical Subject Headings), sendo encontrados os mesmos descritores, e a busca pelos artigos foi feita através do cruzamento entre os descritores e os operadores booleanos AND e OR. Foram utilizados os seguintes descritores para busca dos artigos: método canguru, tempo de internação, unidades hospitalares, prematuridade e seus correlatos na língua inglesa: kangaroo - mother care method, lenghtofstay, hospital units e prematurity. Para o termo kangaroo - mother care method utilizou-se a variação kangaroo method.

A estratégia de busca se delimitou da seguinte forma: kangaroo - mother care method OR kangaroo method AND hospital units AND length of stay; kangaroo - mother care method OR kangaroo method AND length of stay; kangaroo - mother care method AND length of stay AND hospital units AND prematurity; kangaroo - mother care method OR kangaroo method AND length of stay AND prematurity; kangaroo - mother care method $O R$ kangaroo method AND prematurity nas bases de dados Pubmed, Portal Regional da BVS, Cochrane e Scielo. Na base de dados PeDro, foi utilizado asterisco após cada descritor como ferramenta de truncagem.

\section{Critérios de inclusão}

Foram incluídos nesse estudo ensaios clínicos randomizados, publicados no período entre 2008 e 2020, cuja amostra foi composta por indivíduos de ambos os sexos, recém-nascidos prematuros e que tivessem sido tratados com o método canguru de forma isolada ou associada.

\section{Critérios de exclusão}

Foram excluídos estudos que não utilizaram seres humanos, estudos não clínicos, aqueles que não trazem a descrição detalhada da metodologia adotada ou que obtiveram uma avaliação menor que 5/10 na escala PEDro.

\section{Validade interna}

A análise da validade interna dos artigos selecionados foi realizada através da escala PEDro, disponível em http://www.pedro.fhs.usyd.edu.au. A PEDro é uma base de dados específica para estudos que investigam a eficácia de intervenções em fisioterapia ${ }^{39}$. Esta é uma escala que possui 11 itens que foram idealizados com o objetivo de avaliar a confiabilidade e qualidade metodológica de ensaios clínicos randomizados ${ }^{39}$.

Deve ser atribuída a cada item a classificação de sim, se tiver sido contemplado, ou não, caso não tenha sido contemplado. A pontuação final é obtida pela soma de todas as respostas positivas ${ }^{39}$. Cada resposta positiva equivale a um valor de um ponto, menos a do primeiro item, que difere dos outros por estar relacionado com a validade externa do estudo. Dessa forma, a pontuação da escala pode variar de 0 a $10^{39}$.

Os desfechos analisados: ganho de peso, sinais vitais, taxa de crescimento, sucção, analgesia, necessidade de maior suporte na UTIN, tempo de internação e a utilização da posição canguru.

\section{Resultados}

Inicialmente foram encontrados 1.159 artigos científicos nas bases de dados e 22 através de busca secundária em outras fontes. Destes, 311 foram excluídos após aplicação dos filtros (ano de publicação, idade, sexo e pesquisa com humanos). Dos 870 artigos que foram selecionados, 548 foram excluídos por duplicidade; 160 o título não correlacionava o método canguru e o tempo de internação nas unidades hospitalares. Os 162 restantes passaram para etapa de análise de resumo. Destes, 117 foram excluídos por não apresentarem os critérios de inclusão ou não terem relação com assunto estudado. Para avaliação completa, restaram 45 artigos, dos quais 23 não apresentavam os critérios de elegibilidade, pois 18 incluíam recém-nascidos a termos e cinco se tratavam de revisões de literatura, resultando em 22 artigos para essa revisão, conforme descrito na figura 1. 
Figura 1. Fluxo de seleção de artigos o uso do método canguru do recém-nascido prematuro em unidades hospitalares. 2008 - 2020

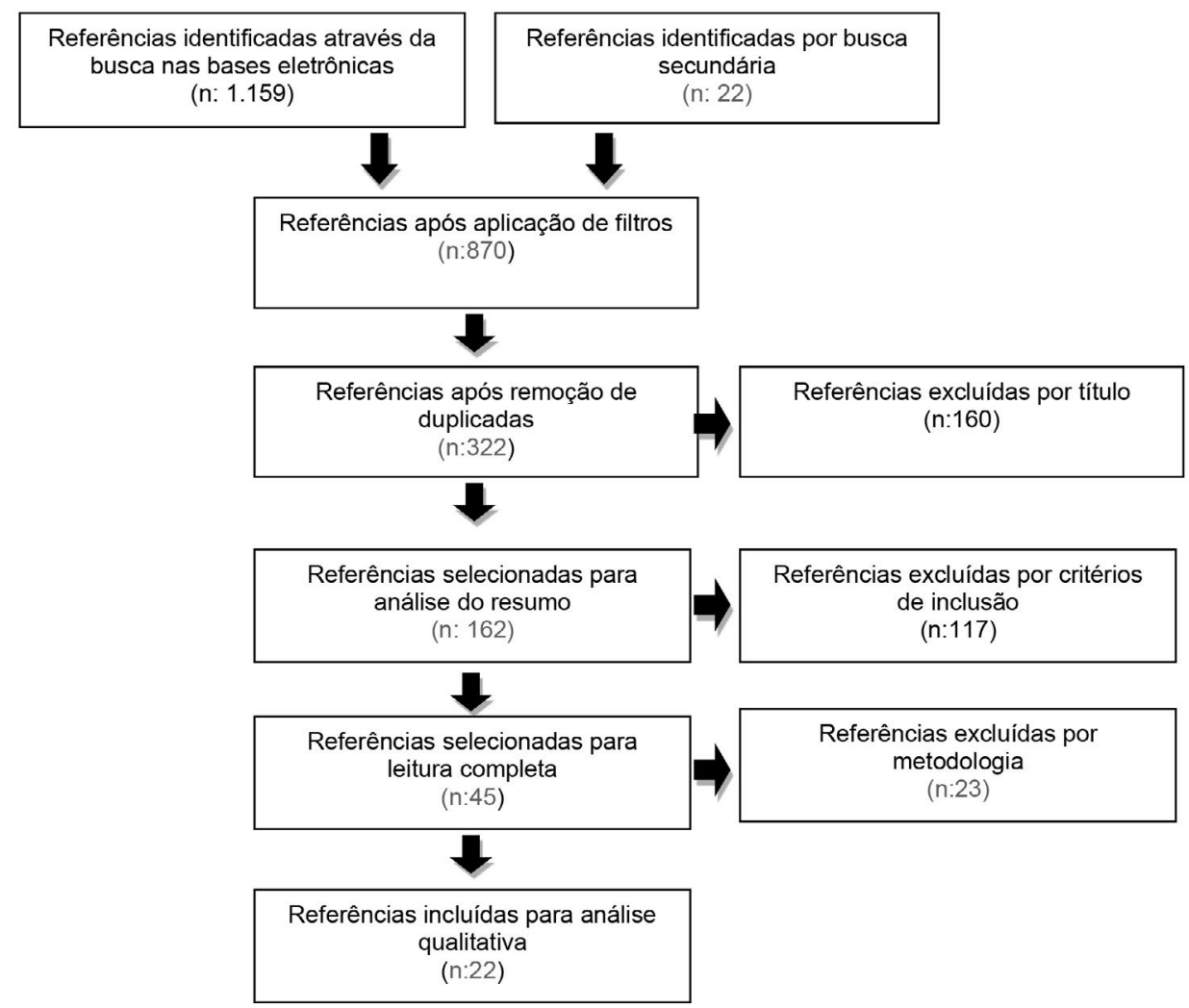

Estes 22 estudos foram encontrados nas bases de dados Portal Regional da BVS, PubMed, Cochrane, Physiotherapy Evidence Database (PEDro) e EBSCOhost, sendo estes quantitativos e experimentais, no período de 2008 a 2020, pertinentes ao tema pesquisado. As amostras iniciais dos artigos selecionados variaram de 20 a 5242 recémnascidos prematuros, e os desfechos estudados foram: taxa de crescimento, tempo de internação, sinais vitais, analgesia, ganho de peso, sistema cardiorrespiratório, sono e regulação hormonal. A avaliação dos sinais vitais foi o parâmetro mais utilizado, sendo visto em treze dos 22 estudos.

A organização e tabulação dos dados extraídos dos 22 artigos estão descritos nas tabelas 1 e 2, de acordo com as seguintes características: autores, ano de publicação, população de estudo e delineamento (Tabela 1) e objetivos, instrumentos de avaliação e os principais achados (Tabela 2). Os dados gerais encontrados nos estudos podem ser vistos na Tabela 3 e a análise qualitativa dos estudos apresentados na Tabela 4. 
Tabela 1. Caracterização dos artigos que abordam o uso do método canguru do recém-nascido prematuro em unidades hospitalares. 2008 - 2020

\begin{tabular}{llcl}
\hline Autor & Ano & Populacao de estudo $\mathbf{( n )}$ & Delineamento da Pesquisa \\
\hline Freire; Garcia; Lamy & 2008 & 95 pacientes & Ensaio clínico randomizado, simples-cego \\
Johnston et al. & 2008 & 61 pacientes & Ensaio cruzado duplo-cego \\
Mwendwa; Musoke; & 2012 & 166 pacientes & Ensaio clínico controlado, randomizado, não cego \\
Wamalwa & 2012 & 20 pacientes & \\
Olmedo et al. & 2013 & Ensaio clínico randomizado \\
Neu; Robinson; Schmiege & 2014 & 126 pacientes & Estudo randomizado, controlado \\
Acharya et al. & 2014 & 64 pacientes & Ensaio clínico randomizado, aleatório \\
Mosayebi et & 2014 & 500 pacientes & Ensaio clínico com delineamento cruzado \\
Bera et al. & 2014 & 80 pacientes & Ensaio clínico controlado \\
Neu et al. & 2014 & 100 pacientes & Ensaio clínico aleatório \\
Gathwala; Singh; Singh & 2015 & 100 pacientes & Estudo controlado aleatório \\
Luong et al. & 2015 & 80 pacientes & Ensaio controlado randomizado \\
Gao et al. & 2016 & 53 pacientes & Ensaio controlado e aleatório \\
Dehghaniet al. & 2016 & Ensaio clínico randomizado duplo-cego \\
Gavhane et al. & 2016 & Ensaio randomizado controlado \\
Dezhdar et al & 2016 & 141 pacientes & Ensaio Clínico Randomizado \\
Sharma; Murki; Pratap & 70 pacientes & Ensaio controlado randomizado \\
Bastani et al. & 2017 & 66 pacientes & Estudo controlado randomizado \\
Aldana Acosta et al. & 2018 & Ensaio clínico randomizado \\
Shukla et al. & 2018 & 100 pacientes & Ensaio clínico randomizado cego \\
Parsa et al. & 2018 & Ensaio quase experimental \\
M. Campbell-Yeo et al. & 2019 & Ensaio clínico randomizado, simples-cego \\
MO Rehman et al. & 2020 & 140 pacientes & Ensaio clínico randomizado \\
\hline
\end{tabular}


Tabela 2. Apresentação dos artigos de acordo com os objetivos e os principais achados em relação ao uso do método canguru do recém-nascido prematuro em unidades hospitalares. 2008 - 2020 (continua)

\begin{tabular}{|c|c|c|c|c|}
\hline Autor/ Ano & Objetivo do estudo & Intervenção & Resultados & Conclusão \\
\hline Johnston et al., 2008 & $\begin{array}{l}\text { Determinar se KMC também } \\
\text { seria eficaz em recém-nascidos } \\
\text { muito prematuros na } \\
\text { diminuição da resposta de dor à } \\
\text { punção do calcanhar }\end{array}$ & $\begin{array}{l}\text { No GI foi realizado o KMC, } \\
\text { durante } 15 \text { minutos antes e ao } \\
\text { longo do procedimento de } \\
\text { punção do calcanhar. No GC, a } \\
\text { criança estava em posição de } \\
\text { prona enrolado num cobertor } \\
\text { na incubadora. Foi avaliada o } \\
\text { perfil de dor do recém-nascido } \\
\text { prematuro (PIPP). }\end{array}$ & $\begin{array}{l}\text { Pontuações PIPP em } 90 \\
\text { segundos pós lança foram } \\
\text { significativamente menores no } \\
\text { estado de KMC, Tempo de } \\
\text { recuperação foi } \\
\text { significativamente mais curto, } \\
\text { ações faciais } \\
\text { Foram significativamente } \\
\text { menores em todos os pontos e } \\
\text { FC foi significativamente } \\
\text { menor em todo os primeiros } 90 \\
\text { segundos na condição KMC. }\end{array}$ & $\begin{array}{l}\text { Os recém-nascidos prematuros } \\
\text { parecem ter mecanismos } \\
\text { endógenos provocada pelo } \\
\text { contato pele-a-pele materna } \\
\text { que diminuem a resposta à dor, } \\
\text { mas não tão poderosa quanto } \\
\text { em RNPT mais velhos. O tempo } \\
\text { de recuperação mais curto em } \\
\text { KMC é clinicamente importante } \\
\text { em ajudar a manter a } \\
\text { homeostase. }\end{array}$ \\
\hline Olmedo et al., 2012 & $\begin{array}{l}\text { Avaliar e comparar as respostas } \\
\text { fisiológicas entre o MMC e a PP, } \\
\text { em RNPT. }\end{array}$ & $\begin{array}{l}\text { No Gl a mãe permaneceu } \\
\text { sentada em uma poltrona com } \\
\text { o tórax despido; em seguida, o } \\
\text { RN foi colocado em posição } \\
\text { vertical e fetal em seu peito em } \\
\text { contato pele a pele, envolto em } \\
\text { uma faixa de malha durante } 60 \\
\text { min. Já o GC os neonatos foram } \\
\text { posicionados somente de } \\
\text { fraldas na incubadora aquecida, } \\
\text { em posição fetal com uma } \\
\text { sustentação toraco abdominal. }\end{array}$ & $\begin{array}{l}\text { As mensurações foram } \\
\text { realizadas por três dias } \\
\text { consecutivos, antes e } 60 \text { min } \\
\text { após a aplicação das técnicas. } \\
\text { No GC, a FR aferida antes foi } \\
\text { significativamente maior do que } \\
\text { a aferida após a intervenção, } \\
\text { nos } 1^{\circ} \text { e } 3^{\circ} \text { dias. Enquanto, no } \\
\text { GC, a FR apresentou diferença } \\
\text { significativa somente no } 3^{\circ} \text { dia. } \\
\text { FC apresentou redução entre os } \\
\text { momentos no } 3^{\circ} \text { dia em ambos } \\
\text { os grupos. }\end{array}$ & $\begin{array}{l}\text { Não foram observadas } \\
\text { alterações na FR, } \mathrm{FC}, \mathrm{T} \text { e SatO } \\
\text { com a aplicação do MMC e PP, } \\
\text { não havendo melhor } \\
\text { desempenho em relação aos } \\
\text { grupos. }\end{array}$ \\
\hline
\end{tabular}


Tabela 2. Apresentação dos artigos de acordo com os objetivos e os principais achados em relação ao uso do método canguru do recém-nascido prematuro em unidades hospitalares. 2008 - 2020 (continuação)

\begin{tabular}{|c|c|c|c|c|}
\hline Autor/ Ano & Objetivo do estudo & Intervenção & Resultados & Conclusão \\
\hline Neu; Robinson; Schmiege, 2013 & $\begin{array}{l}\text { Determinar se a realização do } \\
\text { método canguru em } \\
\text { prematuros saudáveis nas } \\
\text { primeiras oitos emanas de vida } \\
\text { do RN facilita a organização } \\
\text { comportamental precoce e } \\
\text { desenvolvimento. }\end{array}$ & $\begin{array}{l}\text { No G1 pedimos as mães para } \\
\text { manter seus filhos pelo menos } \\
\text { uma hora por dia durante } \\
\text { 8semanas usando o método } \\
\text { canguru. O G2 crianças vestidas, } \\
\text { enrolado em um cobertor, e nos } \\
\text { braços de suas mães. E o G3 } \\
\text { sem restrições de retenção. }\end{array}$ & $\begin{array}{l}\text { O tempo total de retenção } \\
\text { média foi de } 4 \text { a5h/dia e não } \\
\text { diferiu entre os grupos. Mães } \\
\text { realizando método canguru } \\
\text { durante uma média de } \\
59 \text { min/dia no G1, e } 5 \text { e } 9 \\
\text { min/dia no G2 E G3. Os bebês } \\
\text { G1 e G2 tinham pontuações } \\
\text { mais satisfatórias do que o } \\
\text { grupo controle. }\end{array}$ & $\begin{array}{l}\text { O método canguru é } \\
\text { comparado a envolver o RN no } \\
\text { cobertor. Ambos os métodos } \\
\text { podem proporcionar igualdade } \\
\text { de organização } \\
\text { comportamental precoce e de } \\
\text { desenvolvimento benefício para } \\
\text { a criança. }\end{array}$ \\
\hline Acharya et al., 2014 & $\begin{array}{l}\text { Comparar o efeito do MMC e } \\
\text { métodos convencionais no } \\
\text { ganho de peso, ocorrência de } \\
\text { hipotermia, apneia e tempo de } \\
\text { internação hospitalar entre os } \\
\text { bebês. }\end{array}$ & $\begin{array}{l}\text { O Gl foi submetido a KMC por } \\
\text { pelo menos seis horas por dia, e } \\
\text { não excedeu mais do que } \\
\text { quatro sessões. No GC, os } \\
\text { bebês foram adequadamente } \\
\text { vestidos, cobertos e mantidos } \\
\text { com a mãe e, se necessário } \\
\text { foram mantidos sob aquecedor. } \\
\text { A mensuração da temperatura } \\
\text { no Gl foi feita antes, durante e } \\
\text { depois de KMC. No GC a } \\
\text { temperatura foi mensurada a } \\
\text { cada } 4 \text { horas. }\end{array}$ & $\begin{array}{l}\text { A média de ganho de peso foi } \\
\text { maior no Gl e a incidência de } \\
\text { hipotermia foi menor no Gl. O } \\
\text { tempo de internação hospitalar } \\
\text { foi menor no GC. }\end{array}$ & $\begin{array}{l}\text { Bebês com baixo peso inferior a } \\
2000 \text { gramas que recebem KMC } \\
\text { mostram melhor ganho de peso } \\
\text { e têm menos incidência de } \\
\text { hipotermia do que aqueles que } \\
\text { não recebem KMC. }\end{array}$ \\
\hline Mosayebi et al., 2014 & $\begin{array}{l}\text { Avaliar o efeito do MMC para } \\
\text { uma breve duração de } 15 \\
\text { minutos sobre a intensidade da } \\
\text { dor da punção do calcanhar } \\
\text { emrecém-nascidos prematuros } \\
\text { internados em unidades de } \\
\text { cuidados intensivos neonatais. }\end{array}$ & $\begin{array}{l}\text { No Gl, recém-nascidos } \\
\text { receberam MMC } 15 \text { minutos } \\
\text { antes, durante, e dois minutos } \\
\text { após o primeiro processo } \\
\text { depunção do calcanhar. No GC, } \\
\text { recém-nascidos foram mantidos } \\
\text { em PP na incubadora a } 15 \\
\text { minutos antes de lancetar. Para } \\
\text { segunda lancetar de calcanhar, } \\
\text { os neonatos do GI foram } \\
\text { colocados em } \\
\text { incubadoras e GC recebeu CMC. }\end{array}$ & $\begin{array}{l}\text { A pontuação média de } \\
\text { intensidade de dor durante a } \\
\text { intervenção, foi } \\
\text { significativamente menor na } \\
\text { posição KMC. A média de } \\
\text { contagem de intensidade de } \\
\text { dor em dois minutosapós a } \\
\text { intervenção também foi } \\
\text { significativamente menor na } \\
\text { posição KMC. }\end{array}$ & $\begin{array}{l}\text { MMC antes e durante lancetar } \\
\text { calcanhar é um método natural } \\
\text { e fácil de usar, e custo-eficaz } \\
\text { para diminuir a dor emRNPT. É } \\
\text { consistente com a estratégia } \\
\text { moderna de cuidados centrados } \\
\text { na família em unidades } \\
\text { neonatais. }\end{array}$ \\
\hline Bera et al., 2014 & $\begin{array}{l}\text { Avaliar o efeito da KMC } \\
\text { sustentado no crescimento e } \\
\text { desenvolvimento dos recém- } \\
\text { nascidos de baixo peso ate os } \\
12 \text { meses. }\end{array}$ & $\begin{array}{l}\text { O GI realizou o KMC, enquanto } \\
\text { o GC recebeu cuidados } \\
\text { convencionais. Para os bebês } \\
\text { no grupo intervenção foi } \\
\text { realizado KMC até que a criança } \\
\text { completasse } 40 \text { semanas de }\end{array}$ & $\begin{array}{l}\text { Os bebês KMC alcançaram } \\
\text { rapidamente os parâmetros de } \\
\text { crescimento físico semelhantes } \\
\text { para os bebês do GC em } 40 \\
\text { semanas de idade corrigida. }\end{array}$ & $\begin{array}{l}\text { Os lactentes do grupo de KMC } \\
\text { mostraram melhor crescimento } \\
\text { e desenvolvimento físico do que } \\
\text { o grupo de cuidados } \\
\text { convencionais. }\end{array}$ \\
\hline
\end{tabular}


Tabela 2. Apresentação dos artigos de acordo com os objetivos e os principais achados em relação ao uso do método canguru do recém-nascido prematuro em unidades hospitalares. 2008 - 2020 (continuação)

\begin{tabular}{|c|c|c|c|c|}
\hline Autor/ Ano & Objetivo do estudo & Intervenção & Resultados & Conclusão \\
\hline & & $\begin{array}{l}\text { gestação corrigida. Peso, } \\
\text { comprimento e circunferências } \\
\text { de cabeça, tórax e braço foram } \\
\text { avaliados no nascimento e nas } \\
\text { idades corrigidas de } 0,3,6,9 \text { e } \\
12 \text { meses. }\end{array}$ & $\begin{array}{l}\text { Mas, depois disso, eles } \\
\text { superaram esses parâmetros. }\end{array}$ & \\
\hline Neu et al., 2014 & $\begin{array}{l}\text { Para determinar se o método } \\
\text { canguru em prematuros } \\
\text { saudáveis sobre as primeiras } \\
\text { oito semanas de vida do bebê, } \\
\text { facilita a corregulação do } \\
\text { cortisol salivar entre mãe e } \\
\text { bebê }\end{array}$ & $\begin{array}{l}\text { As medidas avaliadas em } \\
\text { ambos os grupos foram } \\
\text { indicadores comportamentais } \\
\text { (duração do choro e duração } \\
\text { das caretas) e indicadores } \\
\text { fisiológicos (FC). As intervenções } \\
\text { foram iniciadas } 30 \text { min antes } \\
\text { das avaliações que foram } \\
\text { realizadas } 30 \text { e } 60 \text { min após o } \\
\text { inicio das intervenções. }\end{array}$ & $\begin{array}{l}\text { A FC foi significativamente } \\
\text { inferior e a duração do choro e } \\
\text { caretas faciais foram menores } \\
\text { no KMC. }\end{array}$ & $\begin{array}{l}\text { Redução do nível de cortisol nas } \\
\text { mães e crianças sugere que a } \\
\text { realização promoveu a queda } \\
\text { esperada nos níveis de } \\
\text { hormônios do } \\
\text { estresse. }\end{array}$ \\
\hline Gathwala; Singh; Singh, 2014 & $\begin{array}{l}\text { Avaliar os benefícios do KMC e } \\
\text { sua aceitabilidade pelas mães e } \\
\text { equipe }\end{array}$ & $\begin{array}{l}\text { O GI realizou o KMC por no } \\
\text { mínimo } 6 \mathrm{~h} \text { por dia, enquanto o } \\
\text { GC recebeu tratamento padrão. } \\
\text { O peso, comprimento e } \\
\text { perímetro cefálico foram } \\
\text { monitorizados diariamente e as } \\
\text { taxas de aleitamento foram } \\
\text { calculadas com base no } \\
\text { histórico obtido das mães. } \\
\text { Todos os bebês foram } \\
\text { acompanhados ate os três } \\
\text { meses. }\end{array}$ & $\begin{array}{l}\text { A temperatura média registrada } \\
\text { durante o MMC foi } \\
\text { significativamente mais } \\
\text { elevado que no grupo de } \\
\text { tratamento de rotina. Episódios } \\
\text { de hipotermia ocorreram mais } \\
\text { frequentemente no GC. O } \\
\text { ganho de peso médio e } \\
\text { comprimento no Gl foi } \\
\text { significativamente mais elevado } \\
\text { do que no GC. }\end{array}$ & $\begin{array}{l}\text { Concluímos que KMC resultou } \\
\text { na melhoria da taxa de } \\
\text { crescimento e } \\
\text { amamentação, e foi bem aceita } \\
\text { por ambas as mães e } \\
\text { enfermeiras da equipe. }\end{array}$ \\
\hline Luong et al., 2015 & $\begin{array}{l}\text { Um estudo anterior sugeriu que } \\
\text { o contato pele a pele alcança } \\
\text { melhor estabilidade fisiológica } \\
\text { no período de transição, } \\
\text { quando comparado com a } \\
\text { incubadora. O objetivo deste } \\
\text { estudo foi replicar o antigo } \\
\text { estudo com uma amostra maior } \\
\text {. }\end{array}$ & $\begin{array}{l}\text { No GC a criança foi então } \\
\text { coberta com um cobertor e } \\
\text { transferido para o } \\
\text { departamento neonatal cerca } \\
\text { de } 30 \text { minutos após o } \\
\text { nascimento. Incubadoras fixado } \\
\text { em } 33^{\circ} \mathrm{C} \text { ou berços foram } \\
\text { usadas. O Gl foi colocado em } \\
\text { um pano sobre o abdômen da } \\
\text { mãe, limpas suavemente e } \\
\text { coberto com um pano novo } \\
\text { permitindo o contato pele a } \\
\text { pele. }\end{array}$ & $\begin{array}{l}\text { O Gl apresentou melhor } \\
\text { transição para a vida extra- } \\
\text { uterina. No KMC as crianças } \\
\text { tiveram significativamente } \\
\text { menor necessidade de suporte } \\
\text { respiratório, fluidos } \\
\text { intravenosos e uso de } \\
\text { antibióticos durante o } \\
\text { restante da estadia hospitalar. }\end{array}$ & $\begin{array}{l}\text { Foi visto que o KMC era } \\
\text { susceptível de ser um ambiente } \\
\text { ideal para recém-nascidos que } \\
\text { pesavam } 1500-2.500 \mathrm{~g} \text { ao } \\
\text { nascer, impedindo a } \\
\text { instabilidade hemodinâmica. } \\
\text { Ideal para ser realizado em } \\
\text { países de baixa renda. }\end{array}$ \\
\hline
\end{tabular}


Tabela 2. Apresentação dos artigos de acordo com os objetivos e os principais achados em relação ao uso do método canguru do recém-nascido prematuro em unidades hospitalares. 2008 - 2020 (continuação)

\begin{tabular}{|c|c|c|c|c|}
\hline Autor/ Ano & Objetivo do estudo & Intervenção & Resultados & Conclusão \\
\hline Gao et al., 2015 & $\begin{array}{l}\text { Para testar a eficácia do Método } \\
\text { Mãe Canguru (MMC) sobre a } \\
\text { dor da punção do calcanhar em } \\
\text { recém-nascidos prematuros. }\end{array}$ & $\begin{array}{l}\text { No primeiro procedimento, o } \\
\text { RN em ambos os grupos não } \\
\text { recebeu nenhuma intervenção } \\
\text { durante os próximos três } \\
\text { procedimentos as crianças do } \\
\text { Gl receberam o Método Mãe } \\
\text { Canguru, enquanto crianças no } \\
\text { GC permaneceram na } \\
\text { incubadora. Choro, caretas e FC } \\
\text { foram avaliados em todas as } \\
\text { fases. }\end{array}$ & $\begin{array}{l}\text { AFC dos prematuros foi } \\
\text { significativamente inferior, e a } \\
\text { duração do choro e caretas } \\
\text { faciais foram significativamente } \\
\text { menores no grupo do Método } \\
\text { Mãe Canguru, do que o GC } \\
\text { desde a fase de coleta de } \\
\text { sangue à fase de recuperação } \\
\text { durante o procedimento. }\end{array}$ & $\begin{array}{l}\text { Nos próximos estudos poderia } \\
\text { ser usado uma ferramenta com } \\
\text { o Premature Infant Pain Profile } \\
\text { (PIPP), o perfil de dor do recém- } \\
\text { nascido prematuro e, além } \\
\text { disso, a comparação de alívio da } \\
\text { dor entre o Método Mãe } \\
\text { Canguru e outras intervenções } \\
\text { não farmacológicas podem ser } \\
\text { examinadas durante } \\
\text { procedimentos dolorosos. }\end{array}$ \\
\hline Dehghaniet al., 2016 & $\begin{array}{l}\text { Determinar o impacto do } \\
\text { método KMC sobre os sinais } \\
\text { vitais e a saturação de oxigênio } \\
\text { arterial de recém-nascidos em } \\
\text { comparação com o método de } \\
\text { cuidados naincubadora a fim de } \\
\text { facilitar este método. }\end{array}$ & $\begin{array}{l}\text { O KMC foi realizado em recém- } \\
\text { nascidos no grupo de estudo } \\
\text { durante uma hora cada dia } \\
\text { durante } 3 \text { dias consecutivos. Os } \\
\text { sinais vitais, incluindo } \\
\text { temperatura, FC, FR por minuto, } \\
\text { e a } \mathrm{SpO}_{2} \text { foram medidos e } \\
\text { registrados antes, durante e } \\
\text { após o processo de cuidar em } \\
\text { ambos os grupos e, em seguida, } \\
\text { foram comparadas e } \\
\text { analisadas. }\end{array}$ & $\begin{array}{l}\text { Os resultados mostraram que } \\
\text { as variações médias de } \\
\text { temperatura e a taxa de } \\
\text { saturação de oxigênio } \\
\text { arterial entre os dois grupos } \\
\text { apresentaram diferenças } \\
\text { significativas em } 3 \text { dias de } \\
\text { exame. Mas não houve } \\
\text { diferenças significativas na FC e } \\
\text { FR. }\end{array}$ & $\begin{array}{l}\text { Em geral, os resultados deste } \\
\text { estudo mostraram que a KMC } \\
\text { pode contribuir para o aumento } \\
\text { da taxa de saturação arterial de } \\
\text { oxigênio, a temperatura e a } \\
\text { estabilidade cardiovascular e } \\
\text { respiratória em recém-nascidos. }\end{array}$ \\
\hline Gavhane et al., 2016 & $\begin{array}{l}\text { Analisar os efeitos a longo prazo } \\
\text { de KMC para crianças } \\
\text { relativamente estáveis MBP } \\
\text { sobre indicadores nutricionais e } \\
\text { condições de alimentação de 6- } \\
12 \text { meses de idade corrigida. }\end{array}$ & $\begin{array}{l}\text { Os RN's foram aleatorizados } \\
\text { para o grupo KMC ou grupo } \\
\text { incubadora. A avaliação incluiu } \\
\text { a medição dos parâmetros } \\
\text { decrescimento em peso, } \\
\text { comprimento e circunferência } \\
\text { cefálica. }\end{array}$ & $\begin{array}{l}\text { Não houve diferença entre os } \\
\text { grupos na incidência de } \\
\text { desnutrição e nanismo. Embora } \\
\text { os bebês do Gl tiveram um } \\
\text { melhor desenvolvimento, peso } \\
\text { e comprimento em comparação } \\
\text { com GC. }\end{array}$ & $\begin{array}{l}\text { KMC grupo não diferem de } \\
\text { forma significativa com o grupo } \\
\text { de KMC em termos } \\
\text { decrescimento a longo prazo e } \\
\text { no padrão de alimentação } 6 \text { a } \\
12 \text { meses de idade corrigida. }\end{array}$ \\
\hline Dezhdar et al.,2016 & $\begin{array}{l}\text { Comparar o efeito do KMC e o } \\
\text { de reter os recém nascidos em } \\
\text { mantas na dor durante } \\
\text { amostragem venosa no RNPT }\end{array}$ & $\begin{array}{l}\text { Os três grupos foram grupo A } \\
\text { (mantas), grupo B (KMC), e o } \\
\text { grupo C (controle). Em todos os } \\
\text { três grupos, a saturação de } \\
\text { oxigênio arterial, frequência } \\
\text { cardíaca e PIPP foram medidos } \\
\text { e registrados em intervalos de } \\
\text { tempo de } 30 \text { segundos antes } \\
\text { de, durante, e } 30,60,90 \text {, e } 120 \\
\text { segundos após a amostragem } \\
\text { de sangue. }\end{array}$ & $\begin{array}{l}\text { As descobertas revelaram que a } \\
\text { dor foi reduzida para uma } \\
\text { grande extensão tanto no G1 } \\
\text { quanto no G2 em comparação } \\
\text { com o grupo controle. No } \\
\text { entanto, não houve diferença } \\
\text { significativa entre G1 E G2. }\end{array}$ & $\begin{array}{l}\text { No presente estudo, foi } \\
\text { demonstrado que, nos dois } \\
\text { grupos de panos eKMC, as } \\
\text { alterações fisiológicas eram } \\
\text { semelhantes uns aos outros e } \\
\text { menos do que no grupo de } \\
\text { controle. }\end{array}$ \\
\hline
\end{tabular}


Tabela 2. Apresentação dos artigos de acordo com os objetivos e os principais achados em relação ao uso do método canguru do recém-nascido prematuro em unidades hospitalares. 2008 - 2020 (continuação)

\begin{tabular}{|c|c|c|c|c|}
\hline Autor/ Ano & Objetivo do estudo & Intervenção & Resultados & Conclusão \\
\hline Sharma; Murki; Pratap, 2016 & $\begin{array}{l}\text { Comparar a eficácia de } \\
\text { cuidados com o bebê no MMC } \\
\text { com cuidados com o bebê na } \\
\text { UCl em lactentes prematuros } \\
\text { estáveis }\end{array}$ & $\begin{array}{l}\text { O Gl as crianças foram } \\
\text { mantidas contato pele a pele, } \\
\text { firmemente ligada à mãe com } \\
\text { os vestidos abertos. Os bebês } \\
\text { do GC foram atendidos na } \\
\text { incubadora no modo } \\
\text { controlador de umidade para a } \\
\text { termorregulação. As mães } \\
\text { foram incentivadas a visitar o } \\
\text { bebê o máximo de vezes } \\
\text { possível. }\end{array}$ & $\begin{array}{l}\text { O comprimento, perímetro } \\
\text { cefálico no momento da alta } \\
\text { foram semelhantes em ambos } \\
\text { os grupos. Não } \\
\text { houve redução significativa no } \\
\text { tempo de internação hospitalar. } \\
\text { Houve aumento significativo no } \\
\text { ganho de peso no grupo MMC. } \\
\text { Houve aumento significativo na } \\
\text { incidência de apneia no grupo } \\
\text { UCl. }\end{array}$ & $\begin{array}{l}\text { MMC é igualmente eficaz como } \\
\text { IIC em melhorar os resultados } \\
\text { do crescimento de pré-termo } \\
\text { estável (peso }<1100 \mathrm{~g} \text { ) }\end{array}$ \\
\hline Bastani et al., 2017 & $\begin{array}{l}\text { Comparar os efeitos da posição } \\
\text { canguru com a retenção nos } \\
\text { braços da mãe e avaliar o sono } \\
\text { e o despertar dos prematuros. }\end{array}$ & $\begin{array}{l}\text { Na fase pré-intervenção todas } \\
\text { as crianças permaneceram em } \\
\text { DD em sua incubadora por } 20 \\
\text { min. Em seguida, as crianças do } \\
\text { Gl foram colocadas sobre suas } \\
\text { mães e no GC as crianças foram } \\
\text { embaladas nos braços das } \\
\text { mães. O período de intervenção } \\
\text { durou } 70 \text { minutos. }\end{array}$ & $\begin{array}{l}\text { No Gl tiveram períodos mais } \\
\text { longos em sono profundo e o } \\
\text { despertar tranquilo durante a } \\
\text { fase de intervenção e menos } \\
\text { tempo no sono leve ou estado } \\
\text { sonolento e no estado } \\
\text { ativamente acordado do que no } \\
\text { GC. }\end{array}$ & $\begin{array}{l}\text { O método canguru parece } \\
\text { aumentar o período de tempo } \\
\text { que prematuros gastam em } \\
\text { sono profundo e quando } \\
\text { acordados permanecem em um } \\
\text { estado mais tranquilo, em } \\
\text { comparação com simplesmente } \\
\text { ter a retenção nos braços de } \\
\text { suas mães. }\end{array}$ \\
\hline Aldana Acosta et al.,2018 & $\begin{array}{l}\text { Avaliação do crescimento inicial } \\
\text { de prematuros recebendo } \\
\text { estimulação cinestésica com } \\
\text { massagem em posição canguru } \\
\text { ou em incubadora. }\end{array}$ & $\begin{array}{l}\text { Os RN's foram aleatorizados } \\
\text { para o grupo KMC ou grupo } \\
\text { incubadora. No grupo } \\
\text { incubadora os pais aplicaram } \\
\text { estimulação cinestésica na } \\
\text { incubadora com o bebê } \\
\text { primeiro em decúbito dorsal e } \\
\text { depois em prono. Já no grupo } \\
\text { KMC o lactente era retirado da } \\
\text { incubadora, com fralda, boné e } \\
\text { meias, e colocado na a posição } \\
\text { prona no tórax da mãe ou pai } \\
\text { em posição canguru }\end{array}$ & $\begin{array}{l}\text { O ganho de peso diário foi } \\
\text { significativamente maior com a } \\
\text { estimulação cinestésica na } \\
\text { posição canguru. }\end{array}$ & $\begin{array}{l}\text { A estimulação cinestésica } \\
\text { precoce na posição canguru } \\
\text { reduz a perda de peso inicial em } \\
\text { bebês entre } 30 \text { - } 33 \text { semanas de } \\
\text { nascimento sem maiores } \\
\text { problemas de saúde. }\end{array}$ \\
\hline Shukla et al., 2018 & $\begin{array}{l}\text { Comparar a eficácia da KMC } \\
\text { com sacarose oral no manejo } \\
\text { da dor em neonatos } \\
\text { prematuros }\end{array}$ & $\begin{array}{l}\text { No grupo KMC, o KMC foi } \\
\text { fornecido pelo menos } 10 \\
\text { minutos antes e foi continuado } \\
\text { de acordo com o protocolo da } \\
\text { unidade após o procedimento } \\
\text { de punção do calcanhar. No } \\
\text { grupo Sacarose, } 0,2 \mathrm{ml} \text { de }\end{array}$ & $\begin{array}{l}\text { A pontuação do PIPP foi menor } \\
\text { no grupo KMC vs. Sacarose, mas } \\
\text { não conseguiu alcançar } \\
\text { significância estatística. }\end{array}$ & $\begin{array}{l}\text { O KMC e a sacarose têm efeitos } \\
\text { comparáveis na eficácia no } \\
\text { manejo da dor em neonatos } \\
\text { prematuros. }\end{array}$ \\
\hline
\end{tabular}


Tabela 2. Apresentação dos artigos de acordo com os objetivos e os principais achados em relação ao uso do método canguru do recém-nascido prematuro em unidades hospitalares. 2008 - 2020 (conclusão)

\begin{tabular}{|c|c|c|c|c|}
\hline Autor/Ano & Objetivo do estudo & Intervenção & Resultados & Conclusão \\
\hline & & $\begin{array}{l}\text { Sacarose } 24 \% \text { foi fornecido } 2 \\
\text { min antes do procedimento. Foi } \\
\text { avaliada o perfil de dor do } \\
\text { recém-nascido prematuro } \\
\text { (PIPP). }\end{array}$ & & \\
\hline Parsa et al., 2018 & $\begin{array}{l}\text { Avaliar o efeito do Método Mãe } \\
\text { Canguru (MMC) nos parâmetros } \\
\text { fisiológicos de bebês } \\
\text { prematuros no Hospital } \\
\text { Fatemiyeh em Hamadan em } \\
2016\end{array}$ & $\begin{array}{l}\text { Eles foram divididos } \\
\text { aleatoriamente em dois grupos } \\
\text { (grupo experimental, } \mathrm{n}=50 \mathrm{e} \\
\text { grupo controle, } \mathrm{n}=50 \text { ). No } \\
\text { grupo experimental, os recém- } \\
\text { nascidos foram tomados } \\
\text { diariamente KMC por uma hora } \\
\text { durante } 7 \text { dias. No grupo } \\
\text { controle, os cuidados de rotina } \\
\text { foram realizados na incubadora. }\end{array}$ & $\begin{array}{l}\text { Após a intervenção, houve } \\
\text { diferença significativa entre os } \\
\text { dois grupos quanto aos indices } \\
\text { fisiológicos dos lactentes } \\
\text { (frequência cardíaca, frequência } \\
\text { respiratória, saturação de } \\
\text { oxigênio no sangue arterial e } \\
\text { temperatura) }\end{array}$ & $\begin{array}{l}\text { Os resultados deste estudo } \\
\text { indicam o efeito do KMC no } \\
\text { aumento dos índices } \\
\text { fisiológicos. Portanto, } \\
\text { recomenda-se que o MMC seja } \\
\text { tomado como um dos cuidados } \\
\text { de rotina de bebês prematuros. }\end{array}$ \\
\hline M. Campbell-Yeo et al., 2019 & $\begin{array}{l}\text { Determinar a eficácia relativa } \\
\text { sustentada de KMC materno, } \\
\text { administrado sozinho ou em } \\
\text { combinação com sacarose } 24 \% \text {, } \\
\text { para reduzir a intensidade da } \\
\text { dor comportamental associada } \\
\text { a procedimentos neonatais de } \\
\text { rotina, em comparação com } \\
\text { sacarose } 24 \% \text { sozinho. }\end{array}$ & $\begin{array}{l}\text { Os RN's foram randomizados } \\
\text { para receber KMC égua (G1), } \\
\text { KMC e sacarose } 24 \% \text { (G2) ou } \\
\text { sacarose } 24 \% \text { (G3) antes de } \\
\text { todos os procedimentos } \\
\text { dolorosos de rotina. A } \\
\text { intensidade da dor, foi } \\
\text { determinada usando o Perfil de } \\
\text { Dor do Bebé Prematuro, em } 30, \\
60 \text { ou } 90 \text { segundos após a } \\
\text { punção do calcanhar. }\end{array}$ & $\begin{array}{l}\text { Os resultados do estudo } \\
\text { demonstraram que não apenas } \\
\text { o KMC proporciona efeitos } \\
\text { redutores da dor semelhantes } \\
\text { aos da sacarose oral } 24 \% \text {, mas } \\
\text { também a combinação de } \\
\text { KCmaterno e sacarose não } \\
\text { parece fornecer benefícios } \\
\text { adicionais na redução da dor. }\end{array}$ & $\begin{array}{l}\text { KMC materno parece } \\
\text { permanecer eficaz ao longo do } \\
\text { tempo e procedimentos } \\
\text { repetidos. O cuidado canguru } \\
\text { parece ter eficácia na redução } \\
\text { da dor comparativa à sacarose } \\
\text { oral para procedimentos } \\
\text { repetidos durante o } \\
\text { internamento. O uso } \\
\text { combinado de KMC e sacarose } \\
\text { não parece trazer benefícios } \\
\text { adicionais }\end{array}$ \\
\hline MO Rehman et al., 2020 & $\begin{array}{l}\text { Medir o impacto do cuidado } \\
\text { intermitente da mãe-canguru } \\
\text { no ganho de peso de neonatos } \\
\text { em uma unidade de terapia } \\
\text { intensiva neonatal. }\end{array}$ & $\begin{array}{l}\text { Os sujeitos foram } \\
\text { randomizados em grupos de } \\
\text { caso e controle. O cuidado mãe- } \\
\text { canguru intermitente foi dado } \\
\text { no grupo caso por sete dias. E o } \\
\text { grupo controle recebeu oq foi } \\
\text { chamado de cuidados } \\
\text { convencionais. }\end{array}$ & $\begin{array}{l}\text { No grupo caso, o ganho de peso } \\
\text { médio foi maior comparado ao } \\
\text { grupo controle. O tempo médio } \\
\text { de permanência no grupo caso } \\
\text { foi significativamente baixo em } \\
\text { comparação ao grupo controle. } \\
\text { A análise multivariada } \\
\text { determinou o efeito da terapia } \\
\text { mãe-canguru como eficaz (p } \\
<0,0001 \text { ). }\end{array}$ & $\begin{array}{l}\text { Os cuidados com o canguru } \\
\text { intermitente mostraram-se } \\
\text { eficazes para melhorar o ganho } \\
\text { de peso em neonatos, além do } \\
\text { tratamento convencional. }\end{array}$ \\
\hline
\end{tabular}

MMC: método mãe canguru; BPN: baixo peso ao nascer; N: número; GC: grupo controle; GI: grupo intervenção; KMC: cuidado mãe canguru; FC: frequência cardíaca; FR: frequência respiratória; SpO2: saturação arterial de oxigênio; GG: grupo glicose; RN: recém-nascido; PP: posição prona; RNPT: recém-nascido prematuro; T: temperatura; UCl: unidade de cuidados intermediário; SCRIP: sistema cardiorrespiratório em prematuros; PIPP: perfil de dor infantil prematura; IC: cuidados incubadora; HR: ritmo cardíaco; HF: energia de alta frequência; LF: energia de baixa frequência; MBP: muito baixo peso; CMC: cuidados médicos convencionais; DD: decúbito dors 
Tabela 3. Dados gerais encontrados nos estudos analisandos o uso do método canguru do recém-nascido prematuro em unidades hospitalares. 2008 - 2020

\begin{tabular}{ccc}
\hline PARÂMETRO AVALIADO & NÚMERO DE ESTUDOS & NÚMERO DE PACIENTES \\
\hline Sinais Vitais & 13 & 1048 \\
Taxa de crescimento & 9 & 1.354 \\
Analgesia & 8 & 5.804 \\
Tempo de internação & 4 & 573 \\
Sono & 1 & 70 \\
Regulação hormonal & 1 & 80 \\
Facilitação comportamental & 1 & 87 \\
e desenvolvimento & & \\
\hline
\end{tabular}

Tabela 4. Qualidade metodológica de acordo com a escala PEDro

\begin{tabular}{|c|c|c|c|c|c|c|c|c|c|c|c|c|}
\hline \multirow[b]{2}{*}{ Autor/Ano } & \multicolumn{12}{|c|}{ Critérios* } \\
\hline & 1 & 2 & 3 & 4 & 5 & 6 & 7 & 8 & 9 & 10 & 11 & $\begin{array}{c}\text { Pontuação } \\
\text { Total }\end{array}$ \\
\hline Freire; Garcia; Lamy, 2008 & 1 & 1 & 1 & 1 & - & - & 1 & 1 & 1 & 1 & 1 & 8 \\
\hline Johnston et al. , 2008 & 1 & 1 & 1 & 1 & 1 & 1 & - & 1 & 1 & 1 & 1 & 9 \\
\hline $\begin{array}{l}\text { Mwendwa; Musoke; } \\
\text { Wamalwa, } 2012\end{array}$ & 1 & 1 & - & 1 & - & - & - & 1 & 1 & 1 & 1 & 6 \\
\hline Olmedo et al., 2012 & 1 & 1 & 1 & 1 & - & - & - & 1 & 1 & 1 & - & 6 \\
\hline $\begin{array}{l}\text { Neu; Robinson; Schmiege, } \\
2013\end{array}$ & 1 & 1 & 1 & 1 & - & - & - & 1 & 1 & 1 & 1 & 7 \\
\hline Acharya et al., 2014 & 1 & 1 & 1 & 1 & - & - & - & 1 & 1 & 1 & 1 & 7 \\
\hline Mosayebi et, 2014 & 1 & 1 & 1 & 1 & 1 & 1 & - & 1 & 1 & 1 & 1 & 9 \\
\hline Bera et al., 2014 & 1 & 1 & - & 1 & - & - & - & 1 & 1 & 1 & 1 & 6 \\
\hline Neu et al., 2014 & 1 & 1 & - & 1 & - & - & - & 1 & 1 & 1 & 1 & 6 \\
\hline $\begin{array}{l}\text { Gathwala; Singh; Singh, } \\
2014\end{array}$ & 1 & 1 & 1 & 1 & - & - & - & 1 & 1 & 1 & 1 & 7 \\
\hline Luong et al., 2015 & 1 & 1 & 1 & 1 & - & - & - & 1 & 1 & 1 & 1 & 6 \\
\hline Gao et al., 2015 & 1 & 1 & 1 & 1 & - & - & - & 1 & 1 & 1 & 1 & 7 \\
\hline Dehghaniet al., 2016 & 1 & 1 & 1 & 1 & 1 & 1 & - & 1 & 1 & 1 & - & 7 \\
\hline Gavhane et al., 2016 & 1 & 1 & 1 & 1 & - & - & - & 1 & 1 & 1 & 1 & 7 \\
\hline Dezhdar et al, 2016 & 1 & 1 & 1 & 1 & - & - & - & 1 & 1 & 1 & 1 & 7 \\
\hline $\begin{array}{l}\text { Sharma; Murki; Pratap, } \\
2016\end{array}$ & 1 & 1 & 1 & 1 & - & - & - & 1 & 1 & 1 & 1 & 7 \\
\hline Bastani et al., 2017 & 1 & 1 & 1 & 1 & - & - & - & 1 & 1 & 1 & - & 6 \\
\hline Aldana Acosta et al.,2018 & 1 & 1 & 1 & 1 & 1 & - & - & 1 & 1 & 1 & 1 & 8 \\
\hline Shukla et al., 2018 & 1 & 1 & 1 & 1 & 1 & - & - & 1 & 1 & 1 & 1 & 8 \\
\hline Parsa et al., 2018 & 1 & 1 & - & 1 & - & - & - & 1 & 1 & 1 & 1 & 6 \\
\hline $\begin{array}{l}\text { M. Campbell-Yeo et al., } \\
2019\end{array}$ & 1 & 1 & 1 & 1 & 1 & - & 1 & 1 & 1 & 1 & 1 & 9 \\
\hline MO Rehman et al., 2020 & 1 & 1 & 1 & 1 & 1 & - & - & 1 & 1 & 1 & 1 & 8 \\
\hline
\end{tabular}

* O critério 1, referente à elegibilidade, não é somado na pontuação final. Os demais critérios são: 2) Os sujeitos foram aleatoriamente distribuídos por grupos; 3) Cegamento da distribuição; 4) Comparação da linha de base; 5) Cegamento dos participantes; 6) Cegamento dos terapeutas; 7) Cegamento dos avaliadores; 8) Acompanhamento adequado; 9) Analise de intenção de tratar; 10) Comparações entre grupos; 11) Estimativas pontuais e variabilidade. A cada resposta positiva é atribuído 1 ponto, podendo o total variar de 0 a 10 pontos. 
Figura 2. APIB - Avaliação do comportamento de bebês prematuros

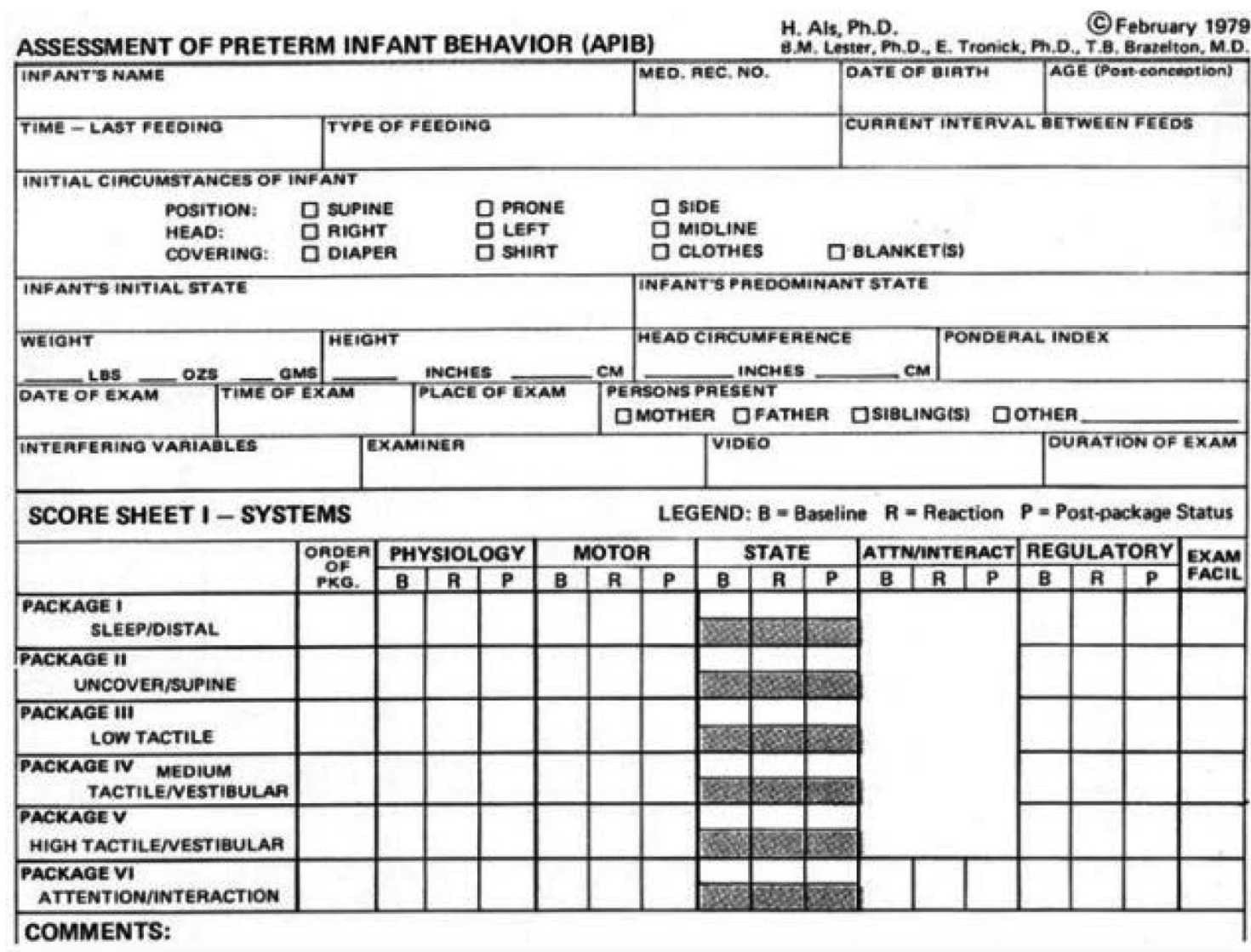

APIB - Avaliação do comportamento de bebês prematuros: apropriada para bebês pré-termos, a termo e em risco de atrasos no desenvolvimento. Esta foca a avaliação das interações dos subsistemas com o ambiente, que são expressas pelo comportamento do bebê. Os seis escores do sistema (Fisiologia, Motor, Estado, Atenção/Interação, Regulamentação, Facilitação do Examinador) variam de 1 a 9. Os escores baixos (1 a 3) denotam graus de regulação comportamental bem modulada e bem organizada e altos escores (7-9) denotam uma regulação comportamental desorganizada e pouco modulada (ALS; DUFFY; MCANULTY, 1988, p.319).

Tabela 5. Escala do Perfil de Dor do Recém-Nascido Prematura

\begin{tabular}{|c|c|c|c|c|}
\hline Indicadores & 0 & 1 & 2 & 3 \\
\hline IG em semanas & $\geq 36$ semanas & 32 a 35 semanas e 6 dias & 28 a 31 semanas e 6 dias & $<28$ semanas \\
\hline \multicolumn{5}{|c|}{ Observar o RN por $15 \mathrm{~s}$} \\
\hline Estado de alerta & $\begin{array}{c}\text { Ativo } \\
\text { Acordado } \\
\text { Olhos abertos } \\
\text { Movimentos faciais presentes }\end{array}$ & $\begin{array}{c}\text { Quieto } \\
\text { Acordado } \\
\text { Olhos abertos } \\
\text { Sem mimica facial }\end{array}$ & $\begin{array}{c}\text { Ativo } \\
\text { Dormindo } \\
\text { Olhos fechados } \\
\text { Movimentos faciais presentes }\end{array}$ & $\begin{array}{c}\text { Quieto } \\
\text { Dormindo } \\
\text { Olhos fechados } \\
\text { Sem mimica facial }\end{array}$ \\
\hline \multicolumn{5}{|l|}{ Anotar $\mathrm{FC}$ e $\mathrm{SpO}_{2}$} \\
\hline FC máxima & $\uparrow 0$ a 4 bpm & $\uparrow 5$ a 14 bpm & $\uparrow 15$ a 24 bpm & $\uparrow \geq 25 \mathrm{bpm}$ \\
\hline Sat. mínima & $\downarrow 0 \%$ a $2,4 \%$ & $\downarrow 2,5 \%$ a $4,9 \%$ & $\downarrow 5 \%$ a $7,4 \%$ & $\downarrow \geq 7,5 \%$ \\
\hline \multicolumn{5}{|l|}{ Observar RN por $30 \mathrm{~s}$} \\
\hline Testa franzida & Ausente & Minimo & Moderado & Máximo \\
\hline Olhos espremidos & Ausente & Mínimo & Moderado & Máximo \\
\hline Sulco naso-labial & Ausente & Minimo & Moderado & Máximo \\
\hline
\end{tabular}

PIPP - Escala Perfil de Dor do Prematuro: é a escala mais indicada para prematuros por levar em consideração as alterações próprias desse grupo de pacientes. Compõe-se de sete parâmetros, incluindo idade gestacional (variando de menores de 28 semanas a maiores de 36 semanas), estado de vigília, frequência cardíaca, taxa de saturação de oxigênio no sangue e expressão facial (testa franzida, olhos espremidos e sulco nasolabial). Cada indicador recebe pontuações entre zero e três. Para qualquer idade gestacional, valores iguais ou menores que 6 indicam a ausência de dor ou presença de dor mínima e valores iguais ou maiores que 12 indicam a presença de dor moderada ou intensa (SILVAet al., 2007, p. 565). 
Figura 3. SCRIP - Estabilidade do sistema cardiorrespiratório em prematuros

\begin{tabular}{|c|c|c|c|}
\hline \multirow[b]{2}{*}{ Variablest } & \multicolumn{3}{|c|}{ Score } \\
\hline & 2 & 1 & 0 \\
\hline Heart rate & $\begin{array}{l}\text { Between } 120 \text { and } 160 \mathrm{BPM} \\
\text { Does not exceed } 200 \mathrm{BPM}\end{array}$ & $\begin{array}{l}\text { Deceleration between } 80 \text { and } \\
100 \mathrm{BPM}\end{array}$ & $\begin{array}{l}\text { Bradycardia }<80 \text { BPM } \\
\text { Tachycardia }>200 \text { BPM }\end{array}$ \\
\hline Respiratory rate & $\begin{array}{l}\text { Between } 30 \text { and } 60 \mathrm{BrPM} \\
\text { Does not exceed } 100 \mathrm{BrPM}\end{array}$ & $\begin{array}{l}\text { Periodic respiratory pauses } \\
\text { (apneas }<10 \text { s, regular } \\
\text { breathing }<20 / \mathrm{s} 3 \text { times) }\end{array}$ & $\begin{array}{l}\text { Apnea }>10 \text { s or tachyp- } \\
\text { nea }>100 \text { RPM }\end{array}$ \\
\hline $\begin{array}{l}\text { Blood oxygen saturation } \\
\text { level }\left(\mathrm{SpO}_{2}\right), \%\end{array}$ & $\mathrm{SpO}_{2}>85 \%$ & $\begin{array}{l}\mathrm{SpO}_{2} \text { period(s) between } 85 \% \\
\text { and } 80 \%\end{array}$ & $\mathrm{SpO}_{2}$ period(s) $<80 \%$ \\
\hline \multicolumn{4}{|c|}{$\begin{array}{l}\text { Abbreviations: BPM, beats per minute; BiPM, breaths per minute; SCRIR, Stability of the Cardiorespiratory System in Premature Infants. } \\
\text { sdapted from Fischer et al."1 }\end{array}$} \\
\hline
\end{tabular}

SCRIP - Estabilidade do sistema cardiorrespiratório em prematuros: esse escore permite avaliar a frequência cardíaca, frequência respiratória e níveis de saturação. É atribuída uma pontuação de zero a dois pontos para cada um desses parâmetros e as pontuações finais podem variar de zero a seis. Quanto maior o escore maior estabilização cardiorrespiratória é apresentada por esse paciente (BATTINet al., 1998, p. 101).

\section{Discussão}

A literatura remete a alguns fatores que são importantes e que influenciam na alta hospitalar de recém-nascidos prematuros. Neste estudo sete parâmetros foram encontrados dentre os 22 estudos analisados. São eles: sinais vitais, taxa de crescimento, analgesia, tempo de internação, sono, regulação hormonal e a facilitação comportamental e desenvolvimento. Os sinais vitais foram os parâmetros mais observados nos estudos, sendo encontrado em 13 dos 22 estudos. Esses sinais são fundamentais para avaliação do recém-nascido, principalmente na unidade de terapia intensiva, já que são indicadores do seu estado de saúde.

Dehghani et al. ${ }^{7}$, Luong et al. .8 e Parsa et al. ${ }^{33}$ compararam o método canguru com os cuidados na incubadora, e os três estudos obtiveram resultados semelhantes em relação aos sinais vitais dos recém nascidos. Nos três estudos, o grupo intervenção apresentou melhora nos seus sinais vitais, especialmente nos valores referentes à temperatura, taxas de saturação arterial e frequência respiratória.

Dehghani et al. ${ }^{7}$ randomizaram 53 pacientes em dois grupos, sendo realizado, no grupo intervenção, uma orientação aos pais, seguido do método durante uma hora em três dias consecutivos, com o contato pele a pele. Os sinais vitais e a saturação foram mensurados cinco minutos antes do procedimento, 30 minutos após o início e no final do processo.

No estudo de Luong et al.. foram randomizados 100 pacientes, e o método foi aplicado durante seis horas todos os dias, até o momento da alta. Associado ao método, as mães foram orientadas a amamentar 30 minutos, três e cinco horas após o nascimento. Os sinais vitais foram mensurados de forma contínua durante todo o procedimento.

Já no estudo de Parsa et al. $\frac{33}{}$ foram divididos aleatoriamente 100 pacientes em dois grupos, experimental e controle. No grupo exepriemental, a posição do metodo canguru foi realizada por uma hora durante sete dias, e os indicadores fisiologicos foram registrados 15 minutos antes da intervenção, 15 minutos após o início da intervenção e após a conclusão da posição. Esses registros foram realizados no primeiro, terceiro, quinto e sétimo dia de intervenção. 
Nos três estudos, a temperatura média aumentou no grupo intervenção em comparação ao grupo controle, assim como a saturação de oxigênio arterial, além da estabilidade cardiovascular e respiratória. Sendo que no estudo de Luong et al. $\frac{.}{\text { a }}$ estabilidade cardiorrespiratória foi avaliada pela pontuação na escala da estabilidade do sistema cardiorrespiratório em prematuros (SCRIP). Os resultados de ambos os estudos corroboram ao achado de Bergman, Linley, Fawcus? No estudo, Bergman, Linley, Fawcus ${ }^{9}$ observaram que os indivíduos que foram submetidos ao método canguru tiveram uma média significativamente maior nas pontuações do SCRIP, além de permanecerem mais estáveis ao longo do tempo de aplicação do método.

No entanto, no estudo de Olmedo et al. $\frac{10}{}$, foram avaliadas e comparadas as respostas fisiológicas entre o método canguru e a posição prona, e não foram observadas alterações na frequência respiratória, frequência cardíaca, temperatura e saturação arterial de oxigênio em nenhum dos grupos estudados, em relação aos dados iniciais, e nem quando comparadas às variáveis entre os grupos. Estes resultados divergentes, comparados aos outros estudos incluídos nesta revisão, podem ser justificados pela adoção de uma metodologia diferente. No estudo de Olmedo et al. ${ }^{10}$, não houve orientações e nem supervisão aos pais, o que não nos traz uma certeza quanto à execução do método proposto no estudo, além de um dos critérios de inclusão ser a estabilidade hemodinâmica dos recém-nascidos.

Outro parâmetro fundamental e que pode diminuir no tempo de internação dos recém-nascidos são as taxas de crescimento. O método canguru foi comparado com os chamados "cuidados convencionais" por cinco estudos, sendo verificado que o grupo que realizou a intervenção obteve resultados significativamente mais elevados referentes ao ganho de peso, comprimento, perímetro cefálico, do tórax e braço11-14,34. No estudo de Mwendwa, Musoke, Wamalwa ${ }^{11}$, durante a primeira sessão as mães foram orientadas a realizar o método corretamente, e todas foram supervisionadas durante as sessões, que duravam oito horas por dia. O peso foi avaliado três vezes por semana, enquanto os perímetros foram avaliados uma vez.
No estudo de Acharya et al. $\frac{12}{\text { foram randomizados }}$ 126 recém nascidos, e as mães foram instruídas. A posição foi realizada por no mínimo seis horas por dia. A pesagem foi realizada duas vezes por dia, já o comprimento e perímetro cefálico foram avaliados na admissão e alta dos pacientes. Já no estudo de Gathwala, Singh e Singh ${ }^{13}$, os pacientes do grupo intervenção realizaram a posição canguru um mínimo de seis horas por dia. Os bebês foram monitorizados quanto a ganho de peso, comprimento e perímetro cefálico. O peso foi registrado diariamente, o comprimento e o perímetro cefálico foram registrados semanalmente.

No entanto, no estudo de Bera et al. $\cdot^{\frac{14}{}}$, foram randomizados 500 recém-nascidos, em que as mães do grupo intervenção receberam orientações e demonstrações sobre o aleitamento materno e sobre o método. No primeiro dia, foi realizada a posição canguru durante uma hora, no segundo dia, duas horas, e no terceiro dia, por três horas, e ainda foram instruídas a continuar a realizar a posição mesmo após a alta. Já no estudo de Rehman et al. ${ }^{34}$, foram randomizados 140 pacientes em grupo intervenção e controle. No grupo intervenção, as mães realizaram a posição do método por uma hora a cada quatro horas, durante sete dias. Nestes cinco estudos, foram obtidas taxas de crescimento mais elevadas no grupo que realizou o método canguru, principalmente no ganho de peso.

Além dos estudos encontrados comparando o método canguru intitulado "cuidados convencionais", Acosta et al. .35 compararam a avaliação do crescimento inicial de prematuros recebendo estimulação cinestésica em posição canguru ou em incubadora. Foram randomizados 66 RN's, onde o grupo da posição do método canguru realizou a estimulação cinestésica na posição prona no tórax da mãe ou pai em posição canguru. Foi visto que o ganho de peso diário foi significativamente maior com a estimulação cinestésica na posiçãocangurudo que no grupo incubadora.

Esses resultados corroboram com os achados de Souza et al. ${ }^{15}$, que afirmaram que o contato pele a pele leva a um maior ganho de peso e de comprimento desses recém nascidos, tendo uma diferença significativa em relação ao grupo que não realizou o método. 
No entanto, nos estudos de Sharma, Murki, Pratap $\frac{16}{16}$ e Gavhane, Eklare, Mohammad ${ }^{17}$, os autores compararam o método canguru com os cuidados na incubadora. Ambos os estudos obtiveram resultados semeIhantes em relação às taxas de crescimento. Os dois estudos citados trazem que o método canguru não difere de forma significativa dos cuidados na incubadora. Sharma, Murki, Pratap ${ }^{16}$ randomizaram 139 pacientes em que as mães eram estimuladas a realizar a posição do método o máximo de tempo possível, assegurando um mínimo de seis horas por dia. Ainda avaliaram o peso, desde a aleatorização até que o recém-nascido completasse 40 semanas de idade corrigida; o comprimento e o perímetro foram avaliados uma vez por semana.

Já Gavhane, Eklare e Mohammad 17 randomizaram 91 pacientes, em que as mães alocadas no grupo do método canguru foram estimuladas a realizar a posição do método um mínimo de oito horas por dia. Todas as avaliações foram feitas e registradas em um período de seis a doze meses. Acredita-se que esses resultados divergentes em ambos os estudos, quando comparados aos presentes nesta revisão, se deram por conta da metodologia aplicada. No estudo de Sharma, Murki, Pratap ${ }^{16}$, o grupo controle também realizou o método canguru, inviabilizando a comparação entre o método e os cuidados convencionais. Já no estudo de Gavhane, Eklare, Mohammad ${ }^{17}$, o grupo controle não realizou o contato pele a pele, mas as mães eram instruídas a realizar massagens e pegar os recém-nascidos no colo o máximo de tempo possível, o que pode ter interferido nos resultados do estudo.

O terceiro parâmetro mais observado nesta revisão é a avaliação da dor nos recém-nascidos, que sofrem repetidos procedimentos dolorosos que podem levar a alterações no desenvolvimento neurocomportamental, motor e declínio a nível cognitivo, além de alterações a nível cerebral, que podem gerar um aumento no tempo de internação ${ }^{\frac{18}{}}$. Nos estudos de Johnston et al. ${ }^{19}$, Mosayebi et al. $\stackrel{20}{ }$, Gao et al. $\underline{21}$ foram comparados a eficácia do método canguru com os cuidados na incubadora. Johnston et al. ${ }^{19}$ randomizaram 61 pacientes e os recém nascidos alocados no grupo intervenção, realizaram a punção do calcanhar 15 minutos depois de iniciado o método. Enquanto no estudo de Mosayebi et al. ${ }^{20}$ foram randomizados 64 pacientes, e inicialmente o grupo intervenção realizou a posição do método que se iniciou 15 minutos antes da punção do calcanhar e posteriormente esse mesmo grupo foi alocado no grupo controle onde os recém nascidos permaneceram na incubadora durante a punção.

Já no estudo Gao et al.21, foram randomizados 80 recém nascidos, e as mães alocadas no grupo intervenção iniciaram a posição do método canguru 30 minutos antes do procedimento de punção e foram orientadas pelas enfermeiras da unidade.

Nos três estudos a dor foi avaliada através da Premature Infant Pain Profile (PIPP), Escala do Perfil de Dor do Recém-Nascido Prematuro, e em todos os estudos a pontuação média de intensidade de dor durante a intervenção foi significativamente menor no grupo que realizou a posição do método canguru, principalmente nos 90 segundos após início da punção.

Os achados dos três estudos corroboram com o resultado encontrado por Akcan, Yiğit e Atıcı22, que avaliaram e registraram as respostas fisiológicas à dor através da PIPP e verificaram que a posição do método canguru começando 30 minutos antes e continuando 10 minutos após um procedimento invasivo tem um efeito positivo na diminuição da dor. Estes efeitos foram observados durante e após um procedimento doloroso em prematuros, já que os escores de dor infantil prematura foram significativamente menores em cada mensuração durante, ou logo após o procedimento invasivo em lactentes no grupo intervenção, se comparado ao controle.

Freire, Garcia e Lamy ${ }^{23}$, Dezhdar et al. ${ }^{24}$, CampbellYeo et al. ${ }^{36}$ e Shukla et al. ${ }^{37}$ também avaliaram a dor dos recém nascidos durante o método canguru. No entanto, Freire, Garcia e Lamy ${ }^{23}$, Campbell-Yeo et al. ${ }^{36}$ e Shukla et al..$^{37}$ compararam o efeito do método com a utilização da glicose oral. No estudo de Freire, Garcia e Lamy $\underline{23}$, foram randomizados 95 recém-nascidos prematuros em três grupos, onde um grupo permanecia na incubadora durante o procedimento doloroso, outro grupo realizava a posição do método canguru e o terceiro grupo recebeu a glicose oral. No que diz respeito aos parâmetros fisiológicos, foi observada uma diferença significativa entre os grupos, onde foram vistos parâmetros melhores no grupo que realizou a posição do método canguru, assim como nos resultados obtidos através da PIPP. 
Já no estudo de Campbell-Yeo et al. $\frac{36}{}$, os 5.242 recémnascidos foram randomizados em três grupos. O primeiro, realizava a posição do metodo canguru associado à água, o segundo grupo realizava a posição do metodo canguru associado à glicose oral, enquanto o terceiro grupo realizou apenas a utilização da glicose oral. Os resultados do estudo demonstraram que não apenas a posição do metodo proporciona efeitos redutores da dor, como esses efeitos permanecem a longo prazo, comparado aos outros grupos, mas também a combinação da posição do método e sacarose não parece fornecer benefícios adicionais na redução da dor.

No entanto, no estudo de Shukla et al. ${ }^{37}$, foram randomizados 100 recém-nascidos em dois grupos, um realizou a posição do método canguru, e outro a utilização da glicose oral. Nos dois grupos, a intervenção, tanto a posição do método quanto a glucose, foram iniciadas no mínimo 10 minutos antes do procedimento doloroso e continuou durante toda realização do procedimento. Foi observado que que os escores da PIPP associados à frequência cardíaca, protuberância da sobrancelha, compressão do olho e sulco nasolabial foram menores no grupo que realizou a posição, mas não atingiu uma diferença estatistiamente significativa. Essa falta de diferença estatistica se justifica, visto que a idade gestacional e os escores relacionadosao estado comportamental foram maiores no grupo que realizou a posição do método em comparação com o grupo da glicose oral.

Contudo, esses resultados não estão concordantes com os obtidos no estudo de Chermont et al. $\underline{25}$, onde foram randomizaram 640 pacientes e avaliaram o efeito analgésico na posição do método canguru em comparação a utilização da Dextrose. Os pacientes foram divididos em quatro grupos, o primeiro permanecia na incubadora, o segundo realizava tratamento oral com dextrose a $25 \%$, o terceiro grupo realizou a posição do método e o quarto uma combinação do tratamento com dextrose oral com o contato pele a pele, na posição do método. Foi verificado que as medidas analgésicas não farmacológicas foram eficazes para o tratamento da dor durante o procedimento, no entanto, a combinação de tratamento oral, com dextrose a $25 \%$ e contato pele a pele na posição do método canguru obteve resultados significativamente melhores do que os outros grupos.
Esses resultados divergentes no estudo de Chermont et al.25, em comparação ao estudo de Freire, Garcia e Lamy ${ }^{23}$, Campbell-Yeo et al. ${ }^{\frac{36}{}}$ e Shukla et al. ${ }^{37}$ podem ser justificados pela adoção da metodologia diferente, já que no estudo de Freire, Garcia e Lamy $\underline{23}$ foram utilizados recém-nascidos a termo e, além disso, a posição do método foi realizada somente por dois minutos antes da realização do procedimento doloroso.

Dezhdar et al. ${ }^{24}$ avaliaram o efeito analgésico na posição do método canguru em comparação a manter o recém-nascido envolto em uma manta e deixá-lo na incubadora. Eles randomizaram 90 recém-nascidos prematuros e dividiram-se em três grupos. Um grupo permaneceu envolto por uma manta na incubadora, o segundo grupo realizou a posição do método e o terceiro grupo apenas permaneceu na incubadora. Foi visto que o grupo que praticou a posição do método canguru e o que permaneceu envolto em uma manta na incubadora obtiveram resultados significativamente melhores que o grupo controle, no entanto, não houve diferenças significativas entre o grupo que realizou a posição do método canguru e o que permaneceu envolto por uma manta.

Esse resultado encontrado por Dezhdar et al. ${ }^{24}$ diverge do que encontramos no estudo de Riddell et al. ${ }^{26}$, onde foi observado que conter o recém-nascido com auxílio de uma manta pode auxiliar na inibição da dor, mas não pode ser considerado mais efetivo que a posição do MC. Nesse estudo ${ }^{26}$, a posição foi realizada apenas 10 minutos antes do procedimento e permaneceu apenas dois minutos após ter sido realizada a punção, o que pode justificar esses resultados divergentes. Além disso, a maioria dos estudos incluídos na revisão se referem à punção do calcanhar. Já no estudo de Dezhdar et al. ${ }^{24}$, o procedimento realizado nos recém-nascidos foi a punção venosa, o que pode ter contribuído na divergência entre os resultados.

Mwendwa, Musoke e Wamalwa ${ }^{11}$ avaliaram também o tempo de permanência hospitalar, além da taxa de crescimento dos recém-nascidos. Como já descrito acima, os autores observaram que o tempo de permanência hospitalar foi menor em dois dias no grupo que realizou a postura do método canguru do que no grupo controle. Quando comparado o tempo de internação hospitalar intragrupo estratificado por 
peso ao nascer, as crianças submetidas à posição do método canguru tiveram uma duração significativamente menor no tempo de permanência hospitalar, reduzindo em cinco dias. Esses resultados vão de encontro ao achado de Ramanathan et al.27, que viram que os indivíduos que foram submetidos à posição do $M C$ reduziram o tempo de internação hospitalar em sete dias e tiveram alta precoce.

Já nos estudos de Sharma, Murki e Pratap ${ }^{16}$ e Acharya et al. ${ }^{12}$, um dos quesitos avaliados foi o tempo de permanência hospitalar, onde os achados não corroboraram com os estudos já vistos nesta revisão. Sharma, Murki e Pratap ${ }^{17}$ verificaram que não houve redução significativa no tempo de internação hospitalar. Esse resultado pode ser justificado pelo fato das mães de ambos os grupos terem realizado a posição do método canguru, o que pode ter influenciado nos resultados. Já Acharya et al. ${ }^{12}$ traz em seu estudo que a permanência hospitalar foi menor no grupo controle do que no grupo que realizou a posição do método, isso pode ser justificado pela heterogeneidade entre os grupos, principalmente em relação ao peso.

Outros fatores, como o sono e a facilitação comportamental dos RNPT, foram encontrados nesta revisão como influenciadores no tempo de permanência hospitalar. Bastani et al. $\frac{28}{}$ randomizaram 70 pacientes e compararam a posição do método canguru com o que eles chamaram de "contenção de retenção de braços", que seria o recém-nascido permanecer no colo da mãe. O sono foi avaliado através do Newborn Individualized Developmental Care and Assessment Program (NIDCAP)a, o Cuidado e Avaliação Individualizada do recém-nascido que exige a observação das crianças de 20 minutos antes e após a intervenção. O período de intervenção durou 70 minutos após a conclusão. Os lactentes foram devolvidos às suas incubadoras, colocados em posição supina e novamente observados durante 20 minutos. Neste estudo, foi visto que a posição do método canguru aumenta significativamente os estados de sono profundo e enquanto acordados, permanecem ativos e tranquilos, além de diminuir significativamente os estados de sono leve e sonolência em comparação com o grupo controle.
Neu, Robinson e Schmiege ${ }^{29}$ avaliaram que a posição do método facilita a organização comportamental precoce e auxilia no desenvolvimento dos RN's. Foram randomizados 87 recém-nascidos em três grupos, sendo que o primeiro realizava a posição do método canguru, o segundo grupo permanecia contido por uma manta nos braços da mãe e o terceiro permanecia na incubadora. A organização comportamental foi avaliada através da avaliação do comportamento infantil pré-termo (APIB). As mães randomizadas no primeiro e segundo grupo foram estimuladas a realizar um mínimo de uma hora por dia durante oito semanas. Os autores verificaram que os lactentes que realizaram a posição do método canguru e os que permaneciam no colo da mãe tiveram pontuações melhores do que as que permaneceram na incubadora, e a pontuação da APIB era semelhante nos pacientes que nasceram a termo.

Os resultados de ambos os estudos corroboram com os achados de Ferber e Makhoul ${ }^{30}$, que avaliaram as respostas neurocomportamentais dos recém-nascidos prematuros. Durante uma observação de uma hora de duração, começando às 4 horas após o nascimento, os recém-nascidos que realizaram a posição do método canguru dormiram mais, estavam em estado de sono mais calmo, exibiram mais movimentos e posturas flexoras e mostraram menos movimentos extensores.

Neu et al. ${ }^{31}$ avaliaram se a posição do método canguru facilita a co-regulação do cortisol salivar, diminuindo o nível de estresse desses recém nascidos. Foram randomizados 79 prematuros em três grupos, onde um grupo realizava a posição do método, o segundo permanecia contido por uma manta nos braços da mãe e o terceiro permanecia na incubadora. As intervenções de cada grupo duraram 60 minutos, durante oito semanas, e as mães alocadas no grupo da posição do método canguru foram orientadas sobre o método. Foi visto que os níveis de cortisol materno e infantil diminuíram durante as intervenções, no entanto, não variaram entre os grupos da posição do método canguru e os que permaneciam nos braços da mãe. A falta de diferenças estaticamente significativas entre os grupos pode ser explicada, já que as

\footnotetext{
a NIDCAP - Programa de Avaliação e Cuidados Individualizados para o Desenvolvimento do Neonato: A abordagem focaliza uma leitura detalhada dos sinais comportamentais individuais de cada bebê. O ambiente e os cuidados são adaptados a fim de realçar os pontos positivos de cada bebê e sua autorregulação, por meio da colaboração entre o bebê e seus pais, que são os principais responsáveis pelos cuidados cotidianos com o recém-nascido e o ajudam a construir o vínculo. O objetivo do NIDCAP é evitar cargas sensoriais e dor inesperadas, e enfatizar os aspectos positivos e as competências do recém-nascido. Esse programa adapta os cuidados médicos intensivos e o ambiente à individualidade do neurodesenvolvimento de cada criança, respondendo assim a suas necessidades clínicas e de desenvolvimento (ALS H, 1986).
} 
mães dos grupos de intervenção, com exceção do grupo controle, foram todas estimuladas a realizarem a posição do método.

Esses resultados são concordantes ao achado de Mitchell et al. $\frac{32}{}$, que afirmam que a posição do método canguru não afetou os níveis de cortisol salivar em recém-nascidos prematuros. Estes resultados divergentes podem ser justificados pela diferente metodologia aplicada, já que no estudo de Mitchell et al. $\underline{32}$ o cortisol foi avaliado após cinco dias de início da posição do método. Já no estudo de Neu et al. ${ }^{31}$, os recém nascidos foram acompanhados e avaliados após oito semanas.

Se observa com esse estudo que, apesar de todos os fatores descritos contribuírem para alta dos recémnascidos, poucos estudos correlacionam diretamente ao tempo de internação. Além disso, há uma falta de padronização em relação à posição do método e o seu tempo de aplicação. Logo, existe a necessidade de mais estudos controlados, randomizados, cegos e com maior poder estatístico, para elucidar de maneira mais consciente e específica o impacto da posição do método canguru no tempo de internação das unidades hospitalares, esclarecendo sua forma de execução.

\section{Conclusão}

Com base na maioria dos artigos incluídos nesta revisão, conclui-se que a utilização da posição do método canguru melhora o quadro dos recém-nascidos prematuros, consequentemente diminui o tempo de internação e traz resultados significativos. Foi visto que a posição do método contribuiu para a melhora dos sinais vitais, quadro álgico e taxas de crescimento, ao mesmo tempo que melhora a estabilização do quadro desses pacientes.

Se observa com esse estudo que apesar de todos os fatores descritos contribuírem para alta dos recémnascidos, poucos estudos correlacionam especificamente ao tempo de internação.
Além disso, há uma falta de padronização em relação a posição do método e o seu tempo de aplicação. Logo, existe a necessidade de mais estudos controlados, randomizados, cegos e com maior poder estatístico para elucidar de maneira mais consciente e específica o impacto da posição do método canguru no tempo de internação das unidades hospitalares, esclarecendo sua forma de execução.

\section{Contribuições dos autores}

Ambas as autoras participaram de todas as etapas, da concepção à redação do artigo.

\section{Conflitos de interesses}

Nenhum conflito financeiro, legal ou político envolvendo terceiros (governo, empresas e fundações privadas, etc.) foi declarado para nenhum aspecto do trabalho submetido (incluindo, mas não se limitando a subvenções e financiamentos, participação em conselho consultivo, desenho de estudo, preparação de manuscrito, análise estatística, etc.).

\section{Referências}

1. Almeida TSO, Lins RP, Camelo AL, Mello DCCL. Investigação sobre os Fatores de Risco da Prematuridade: uma Revisão Sistemática. Rev. bras. ciênc. Saúde [Internet]. 2013;17(3):3018. Disponível em: http://periodicos.ufpb.br/ojs/index.php/rbcs/ article/view/13674

2. Vettorazzi J, Valério EG, Ramos JGL, Costa SHAM, Müller ALL. Prematuridade. Prematuridade. In: Martins-Costa S, Ramos JGL, Magalhães JA, Passos E, Freitas F. Rotinas em Obstetricia. $7^{a}$. ed. [S.I.]: Artmed; 2017. p. 69-80.

3. Schmidt KT, Bessa JB, Rodrigues BC, Arenas MA, Corrêa DAM, Higarashi IH. Recém-nascidos prematuros e alta hospitalar: Uma revisão. Rev Rene [Internet]. 2011;12(4):849-58. Disponível em: https://www.redalyc.org/pdf/3240/324027977024.pdf

4. Méio MDBB, Lopes CS, Morsch DS. Fatores prognósticos para o desenvolvimento. Rev. Saúde Pública. 2003;37(3):311-8. http:// dx.doi.org/10.1590/50034-89102003000300008

5. Rabelo MZS, Chaves EMC, Cardoso MVLML, Sherlock MSM. Sentimentos e expectativas das mães na alta hospitalar do recémnascido prematuro. Acta paul. enferm. 2007;20(3):333-7. http:// dx.doi.org/10.1590/S0103-21002007000300015 
6. Ministério da Saúde (Brasil). Secretaria de Atenção à Saúde. Departamento de Ações Programáticas Estratégicas. Atenção humanizada ao recém-nascido: Método Canguru: manual técnico - 3. ed. Brasília: Ministério da Saúde; 2017.

7. Dehghani K, Movahed ZP, Dehghani H, Nasiriani K. A randomized controlled trial of kangaroo mother care versus conventional method on vital signs and arterial oxygen saturation rate in newborns who were hospitalized in neonatal intensive care unit. J Clin Neonatol [Internet]. 2015;4:26-31. Disponível em: https://www.jcnonweb.com/text.asp?2015/4/1/26/151163

8. Chi Luong K, Long Nguyen T, Huynh Thi DH, Carrara HP, Bergman NJ. Newly born low birthweight infants stabilise better in skin-to-skin contact than when separated from their mothers: a randomised controlled trial. Acta Paediatr. 2016;105(4):381-90. https://doi.org/10.1111/apa.13164

9. Bergman NJ, Linley LL, Fawcus SR. Randomized controlled trial of skin-to-skin contact from birth versus conventional incubator for physiological stabilization in 1200- to 2199gram newborns. Acta Paediatr. 2004;93(6):779-85. https://doi. org/10.1111/j.1651-2227.2004.tb03018.x

10. Olmedo MD, Gabas GS, Merey LSF, Souza LS, Muller KTC, Santos MLM, et al. Respostas fisiológicas de recém-nascidos prétermo submetidos ao Metódo Mãe-Canguru e a posição prona. Fisioter. Pesqui. 2012;19(2):115-21. http://dx.doi.org/10.1590/ S1809-29502012000200005

11. Mwendwa AC, Musoke RN, Wamalwa DC. Impact of partial kangaroo mother care on growth rates and duration of hospital stay of low birth weight infants at the kenyatta national hospital, nairobi. East Afr Med J. 2012;89(2):53-8. Citado em: PMID: 26845812

12. Acharya N, Singh R, Bhatta N, Poudel P. Randomized Control Trial of Kangaroo Mother Care in Low Birth Weight Babies at a Tertiary Level Hospital. JNPS. 2014;34(1):18-3. https://doi. org/10.3126/jnps.v34i1.8960

13. Gathwala G, Singh B, Singh J. Effect of Kangaroo Mother Care on physical growth, breastfeeding and its acceptability. Trop Doct. 2010;40(4):199-202. https://doi.org/10.1258/td.2010.090513

14. Bera A, Ghosh J, Singh AK, Hazra A, Mukherjee S, Mukherjee R. Effect of kangaroo mother care on growth and development of low birthweight babies up to 12 months of age: a controlled clinical trial. Acta Paediatr. 2014;103(6):643-50. https://doi. org/10.1111/apa.12618

15. Souza AKCM, Tavares ACM, Carvalho DGL, Araújo VC. Ganho de peso em recém-nascidos submetidos ao contato pele a pele. Rev. CEFAC. 2018;20(1):53-60. https://doi.org/10.1590/1982$\underline{021620182018317}$
16. Sharma D, Murki S, Pratap OT. The effect of kangaroo ward care in comparison with "intermediate intensive care" on the growth velocity in preterm infant with birth weight <1100 g: randomized control trial. Eur J Pediatr. 2016;175(10):1317-24. https://doi.org/10.1007/s00431-016-2766-y

17. Gavhane S, Eklare D, Mohammad H. Long Term Outcomes of Kangaroo Mother Care in Very Low Birth Weight Infants. J Clin Diagn Res. 2016;10(12):SC13-SC15. https://doi.org/10.7860/ jcdr/2016/23855.9006

18. Anand KJ. Effects of perinatal pain and stress. Prog Brain Res. 2000;122:117-29. https://doi.org/10.1016/s0079-6123(08)62134-2

19. Johnston CC, Filion F, Campbell-Yeo M, Goulet C, Bell L, McNaughton $\mathrm{K}$, et al. Kangaroo mother care diminishes pain from heel lance in very preterm neonates: a crossover trial. BMC Pediatr. 2008;8:13. https://doi.org/10.1186/1471-2431-8-13

20. Mosayebi Z, Javidpour M, Rahmati M, Hagani H, Movahedian $\mathrm{AH}$. The Effect of Kangaroo Mother Care on Pain From Heel Lance in Preterm Newborns Admitted to Neonatal Intensive Care Unit: a Crossover Randomized Clinical Trial. J Compr Ped. 2014;5(4):e22214. https://dx.doi.org/10.17795/compreped-22214

21. Gao H, Xu G, Gao H, Dong R, Fu H, Wang D, et al. Effect of repeated Kangaroo Mother Care on repeated procedural pain in preterm infants: A randomized controlled trial. Int J Nurs Stud. 2015;52(7):1157-65. https://doi.org/10.1016/j.ijnurstu.2015.04.006

22. Akcan E, Yiğit R, Atici A. The effect of kangaroo care on pain in premature infants during invasive procedures. Turk J Pediatr. 2009;51(1):14-8. Citado em: PMID: 19378885

23. Freire NBS, Garcia JBS, Lamy ZC. Evaluation of analgesic effect of skin-to-skin contact compared to oral glucose in preterm neonates. Pain. 2008;139(1):28-33. https://doi.org/10.1016/j. pain.2008.02.031

24. Dezhdar S, Jahanpour F, Firouz Bakht S, Ostovar A. The Effects of Kangaroo Mother Care and Swaddling on Venipuncture Pain in Premature Neonates: A Randomized Clinical Trial. Iran Red Crescent Med J. 2016;18(4):e29649. https://doi.org/10.5812/ ircmj.29649

25. Chermont AG, Falcão LF, Silva EHLS, Balda RCX, Guinsburg R. Skin-to-skin contact and/or oral $25 \%$ dextrose for procedural pain relief for term newborn infants. Pediatrics. 2009;124(6):e1101-7. https://doi.org/10.1542/peds.2009-0993

26. Riddell RRP, Racine NM, Turcotte K, Uman LS, Horton RE, Osmun LD, et al. Non-pharmacological management of infant and young child procedural pain. Cochrane Database Syst Rev. 2011;(10):CD006275. https://doi.org/10.1002/14651858.cd006275. pub2 
27. Ramanathan K, Paul VK, Deorari AK, Taneja U, George G. Kangaroo Mother Care in very low birth weight infants. Indian J Pediatr. 2001;68(11):1019-23. https://doi.org/10.1007/bf02722345

28. Bastani F, Rajai N, Farsi Z, Als H. The Effects of Kangaroo Care on the Sleep and Wake States of Preterm Infants. J Nurs Res. 2017;25(3):231-9. Citado em: PMID: 28481819

29. Neu M, Robinson J, Schmiege SJ. Influence of holding practice on preterm infant development. MCN Am J Matern Child Nurs. 2013;38(3):136-43. https://doi.org/10.1097/ nmc.0b013e31827ca68c

30. Ferber SG, Makhoul IR. The effect of skin-to-skin contact (kangaroo care) shortly after birth on the neurobehavioral responses of the term newborn: a randomized, controlled trial. Pediatrics. 2004;113(4):858-65. https://doi.org/10.1542/ peds.113.4.858

31. Neu M, Hazel NA, Robinson J, Schmiege SJ, Laudenslager M. Effect of holding on co-regulation in preterm infants: a randomized controlled trial. Early Hum Dev. 2014;90(3):141-7. https://doi.org/10.1016/j.earlhumdev.2014.01.008

32. Mitchell AJ, Yates CC, Williams DK, Chang JY, Hall RW. Does daily kangaroo care provide sustained pain and stress relief in preterm infants? J Neonatal Perinatal Med. 2013;6(1):45-52. https://doi.org/10.3233/npm-1364212

33. Parsa P, Karimi S, Basiri B, Roshanaei G. The effect of kangaroo mother care on physiological parameters of premature infants in Hamadan City, Iran. Pan Afr Med J. 2018;30:89. https://doi. org/10.11604/pamj.2018.30.89.14428
34. Rehman MOU, Hayat S, Gul R, Waheed KAI, Victor G, Khan $M Q$. Impact of intermittent kangaroo mother care on weight gain of neonate in nicu: Randomized control trial. J Pak Med Assoc. 2020;70(6):973-7. https://doi.org/10.5455/jpma.45123

35. Acosta ACA, Tessier R, Charpak N, Tarabulsy G. Randomised controlled trial on the impact of kinesthetic stimulation on early somatic growth of preterm infants in Kangaroo position. Acta Paediatrica. 2019;108(7):1230-6. https://doi.org/10.1111/ apa. 14675

36. Campbell-Yeo M, Johnston CC, Benoit B, Disher T, Caddell $\mathrm{K}$, Vincer $\mathrm{M}$, et al. Sustained efficacy of kangaroo care for repeated painful procedures over neonatal intensive care unit hospitalization: a single-blind randomized controlled trial. Pain. 2019;160(11):2580-8. https://doi.org/10.1097/j. pain. 0000000000001646

37. Shukla V, Chapla A, Uperiya J, Nimbalkar A, Phatak A, Nimbalkar S. Sucrose vs. skin to skin care for preterm neonatal pain control-a randomized control trial. J Perinatol. 2018;38(10):1365-9. https://doi.org/10.1038/s41372-018-0193-9

38. Mendes KDS, Silveira RCCP, Galvão CM. Revisão Integrativa: Método de Pesquisa Para a Incorporação de Evidências na Saúde e na Enfermagem. Texto Contexto Enferm. 2008;17(4):758-64. https://doi.org/10.1590/S0104-07072008000400018

39. Shiwa SR, Costa LOP, Moser ADL, Aguiar IC, Oliveira LVF. PEDro: a base de dados de evidências em fisioterapia. Fisioter mov. 2011;24(3):523-33. https://doi.org/10.1590/50103$\underline{51502011000300017}$ 